\title{
A native chemical ligation strategy to overcome side reactions during Fmoc-based synthesis of $\mathrm{C}$-terminal cysteine-containing peptides
}

\author{
Dominique Lelièvre, Victor P. Terrier, Agnès F. Delmas, Vincent Aucagne \\ Centre de Biophysique Moléculaire, CNRS UPR 4301, Rue Charles Sadron 45071 Orléans cedex 2, \\ France.
}

Supporting Information

Table of contents:

1) General information $\quad S 2$

2) General procedures for solid phase peptide synthesis $\quad$ S3

3) Synthesis of [1-51] AhPDF1.1b (1) via standard Fmoc-SPPS S4

4) Studies on the $\mathrm{N}$-acylation of the $\mathrm{N}-\mathrm{Hnb}$-Cys device with Fmoc-Pro-OH S9

a- Preliminary results $\quad$ S9

b- Synthesis of $\mathrm{N}$-Hnb-Cys resin S5 $\quad \mathrm{S} 11$

c- Study of the intramolecular $N \rightarrow O$ shift kinetics $\quad \mathrm{S} 12$

d- Selective cleavage of the Hnb esters $\quad \mathrm{S} 13$

5) Synthesis of [1-50] AhPDF1.1b-(Hnb)C(StBu)G-NH ${ }_{2}(2) \quad$ S24

6) Synthesis of [1-51] AhPDF1.1b (1) via NCL S28

a- Optimization of the NCL conditions on purified peptide $2 \quad$ S28

b- Application to the crude peptide $2 \quad$ S31

7) Application to the synthesis of [1-51] AhPDF1.5 (7) S33

a- Synthesis of [1-50] AhPDF1.5-(Hnb)C(StBu)G-NH $\mathrm{NH}_{2}(6) \quad$ S33

b- Synthesis of 7 via NCL $\quad$ S35 


\section{General information}

All reagents and solvents were used without further purification. Protected amino acids, Rink's amide linker and HCTU were purchased from Merck Biosciences (Nottingham, UK). H-Cys(Trt)-Trityl-ChemMatrix resin was purchased from PCAS BioMatrix (St-Jean-sur-Richelieu, Québec). Aminomethyl TentaGel $\mathrm{R}$ resin was purchased from Rapp polymers (Tuebingen, Germany). Peptide synthesis grade DMF and HATU were purchased from Applied Biosystems (Courtaboeuf, France). Ultrapure water was obtained using a Milli-Q water system from Millipore (Molsheim, France). All other chemicals were from Sigma Aldrich (St-Quentin-Fallavier, France) and solvents from SDS-Carlo Erba (Val de Reuil, France).

${ }^{1} \mathrm{H}$ and ${ }^{13} \mathrm{C}$ NMR spectra were recorded on a Bruker AVANCE III 600 instrument, at a constant temperature of $298 \mathrm{~K}$. Chemical shifts are reported in parts per million from low to high field and referenced to tetramethylsilane (TMS). Coupling constants (J) are reported in hertz $(\mathrm{Hz})$. Standard abbreviations indicating multiplicity were used as follows: $s=$ singlet, $d=$ doublet, $d d=$ doublet of doublets, $t=$ triplet, $m=$ multiplet, $b=$ broad signal.

High resolution ESI-MS analyses were performed on a maXis ${ }^{\mathrm{TM}}$ ultra-high-resolution Q-TOF mass spectrometer (Bruker Daltonics, Bremen, Germany), using the positive mode. MALDI-TOF analyses were performed on an Ultraflex instrument (Bruker Daltonics, Bremen, Germany) equipped with a 337-nm nitrogen laser and a gridless delayed extraction ion source. In the latter case, the sample was co-crystallized with a solution of a-cyano-4-hydroxy-cinnamic acid (HCCA) as a matrix. The reported $\mathrm{m} / \mathrm{z}$ values correspond to the monoisotopic ions if not specified otherwise. Peptides incorporating an $\mathrm{N}$-(2-hydroxy-5-nitrobenzyl) group displayed a typical MALDI fragmentation pattern, consisting in -16 $\mathrm{Da}$ and -34 Da minor peaks in addition to the $[\mathrm{MH}]^{+}$peak.

HPLC analyses and semi-preparative purifications were carried out on a LaChrom Elite system equipped with a Hitachi L-2130 pump, a Hitachi L-2455 diode array detector and a Hitachi L-2200 autosampler. Nucleosil C18 $(300 \AA$, $5 \mu \mathrm{m}, 250 \times 4.6$ $\mathrm{mm}, 1 \mathrm{~mL} / \mathrm{min}$ flow rate) or Chromolith HighResolution RP-18e $(150 \AA$, $100 \times 4.6$ $\mathrm{mm}, 3 \mathrm{~mL} / \mathrm{min}$ flow rate) columns were used for analysis and Nucleosil C18 (300 $\AA, 5$ $\mu \mathrm{m}, 250 \times 10 \mathrm{~mm}, 3 \mathrm{~mL} / \mathrm{min}$ flow rate) for purification. Chromatography was conducted at room temperature unless otherwise mentioned. Solvents $A$ and $B$ were $0.1 \%$ TFA in $\mathrm{H}_{2} \mathrm{O}$ and $0.1 \%$ TFA in MeCN, respectively. Each gradient was followed by a washing step (up to $95 \%$ B/A over 0.5 min for the HR Chromolith; over 1 min for the Nucleosil C18 column) to identify eventual co-products not eluted during the gradient.

LC/HRMS analyses were carried out on a Ultimate ${ }^{\circledR} 3000$ RSLC HPLC system (Dionex, Germering, Germany), coupled with the maXis ${ }^{\mathrm{TM}}$ mass spectrometer and 
fitted with a Zorbax 300 SB-C18 RRHD (300 A, $1.8 \mu \mathrm{m}, 100 \times 2.1 \mathrm{~mm}, 0.5 \mathrm{~mL} / \mathrm{min}$ flow rate, $40{ }^{\circ} \mathrm{C}$ ) column. Solvents $A$ and $B$ were $0.1 \%$ formic acid in $\mathrm{H}_{2} \mathrm{O}$ and $0.08 \%$ formic acid in MeCN, respectively. Gradient: 3\% B/A for $0.6 \mathrm{~min}$, then 3 to $50 \% \mathrm{~B} / \mathrm{A}$ over $10.8 \mathrm{~min}$.

\section{General procedures for solid phase peptide synthesis}

Fmoc-based solid phase peptide syntheses (SPPS) were carried out either on a Prelude synthesizer from Protein Technologies or an ABI433 synthesizer from Applied Biosystems. Standard side-chain protecting groups were used for peptide elongation: $\operatorname{Arg}(\mathrm{Pbf}), \mathrm{Asn}(\mathrm{Trt}), \mathrm{Asp}(\mathrm{OtBu}), \mathrm{Cys}(\mathrm{Trt}), \mathrm{Glu}(\mathrm{OtBu}), \mathrm{G} \ln (\mathrm{Trt})$, His(Trt), Lys(Boc), Ser(tBu), Thr(tBu), Trp(Boc) and $\operatorname{Tyr}(t \mathrm{Bu})$, and Cys(StBu) for the synthesis of the $\mathrm{N}-\mathrm{Hnb}$-Cys thioesterification device.

Syntheses on the Prelude synthesizer were performed at a $25 \mu \mathrm{mol}$ scale. Protected amino acids ( $0.25 \mathrm{mmol}, 10$ equiv.) were coupled using HCTU (98 mg, $0.238 \mathrm{mmol}$, 9.5 equiv.) and $\operatorname{Pr}_{2} \mathrm{NEt}(87 \mu \mathrm{L}, 0.5 \mathrm{mmol}, 20$ equiv.) in NMP (3 mL) for $30 \mathrm{~min}$. Capping of eventual unreacted amine groups was achieved by treatment with acetic anhydride (143 $\mu \mathrm{L}, 1.51 \mathrm{mmol}, 60$ equiv.), $i \operatorname{Pr}_{2} \mathrm{NEt}(68 \mu \mathrm{L}, 0.39 \mathrm{mmol}, 15.5$ equiv.) and HOBt (6 mg, $0.044 \mathrm{mmol}, 1.8$ equiv.) in DMF (3 mL) for $7 \mathrm{~min}$. Fmoc group was removed by three successive treatments with $20 \%$ piperidine in NMP (3 mL) for 3 min. Syntheses on the ABI433 synthesizer were performed at a $100 \mu \mathrm{mol}$ scale, employing the same protocols, with an adjustment of the amounts of reagents and solvents according to a $100 \mu \mathrm{mol}$ scale, in order to achieve the same reagents stoichiometries and reaction concentrations.

The crude peptides were deprotected and cleaved from the resin through a treatment with $\mathrm{TFA} / \mathrm{H}_{2} \mathrm{O} / \mathrm{DODT}^{1} / \mathrm{Pr}_{3} \mathrm{SiH} /$ phenol $(78 / 5 / 10 / 2 / 5)$ for $3 \mathrm{~h}$, and the peptide was precipitated by dilution into an ice-cold 1:1 diethyl ether/petroleum ether mixture, recovered by centrifugation and further washed three times with diethyl ether.

\footnotetext{
${ }^{1}$ DODT: 2,2'-(Ethylenedioxy) diethanethiol
} 


\section{Synthesis of [1-51] AhPDF1.1b (1) via standard Fmoc-SPPS}

Amino acids sequence of [1-51] AhPDF1.1b (1):

${ }^{1}$ ZRLCEKPSGTWSGVCGNNGACRNQCIRLEKARHGSCNYVFPAHKCICYFP ${ }^{51} \mathrm{C}-\mathrm{OH}$ $Z$ = pyroglutamic acid
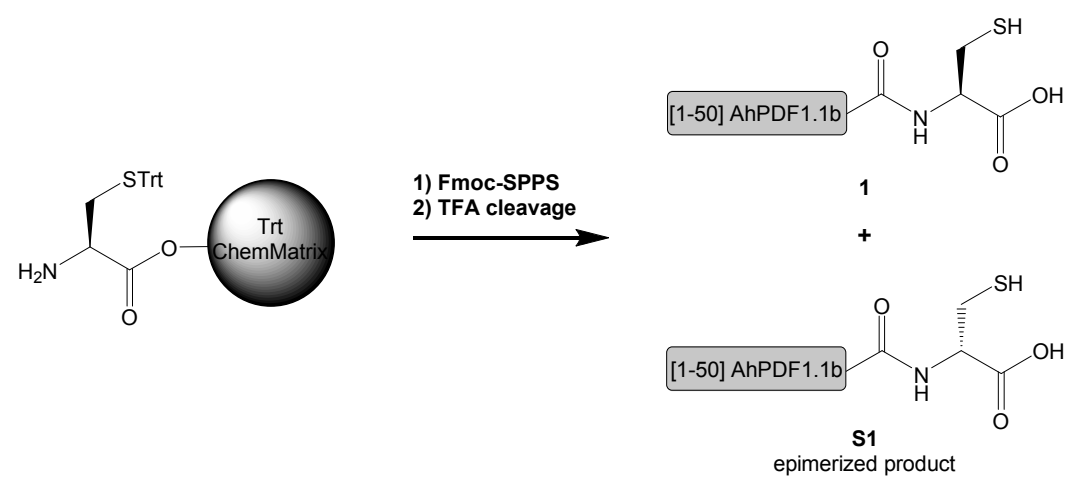

Supplementary scheme S1: Synthesis of peptide 1 via standard Fmoc-SPPS. Synthesis was performed on a 433A synthesizer, starting from H-Cys(Trt)-TritylChemMatrix resin (323 mg, loading: $0.31 \mathrm{mmol} / \mathrm{g}, 100 \mu \mathrm{mol}$ ).

During the SPPS elongation of [1-51] AhPDF1.1b, small aliquots of peptide-resin were withdrawn after 9 and 31 cycles. These aliquots were deprotected and cleaved (protocol p S3) to afford crude [42-51] AhPDF1.1b S2 and [20-51] AhPDF1.1b S3 that were analyzed by HPLC and MS in order to quantify the amount of epimerization along the SPPS process. In both cases, a minor, later eluted peak ( $8 \%$ and $27 \%$, respectively) was observed showing the same $\mathrm{m} / \mathrm{z}$ as the expected products $\mathbf{S 2}$ and S3, respectively, attributed to the epimerization of the C-terminal L-Cys into D-Cys (co-products S2' and S3', respectively). The L/D ratio was determined by integration of the respective HPLC peaks at $280 \mathrm{~nm}$. 
MALDI-TOF $(\mathrm{m} / \mathrm{z})$ : $[\mathrm{MH}]^{+}$calcd. for $\mathrm{C}_{53} \mathrm{H}_{78} \mathrm{~N}_{13} \mathrm{O}_{12} \mathrm{~S}_{3}: 1184.506$, found: 1184.528 . HPLC analysis: $t_{R}=15.8$ min (Nucleosil, gradient: $20-40 \%$ B/A over 30 min).

S2'

MALDI-TOF $(\mathrm{m} / \mathrm{z}):[\mathrm{MH}]^{+}$calcd. for $\mathrm{C}_{53} \mathrm{H}_{78} \mathrm{~N}_{13} \mathrm{O}_{12} \mathrm{~S}_{3}: 1184.506$, found: 1184.518 . HPLC analysis: $t_{R}=16.7$ min (Nucleosil, gradient: $20-40 \%$ B/A over 30 min).

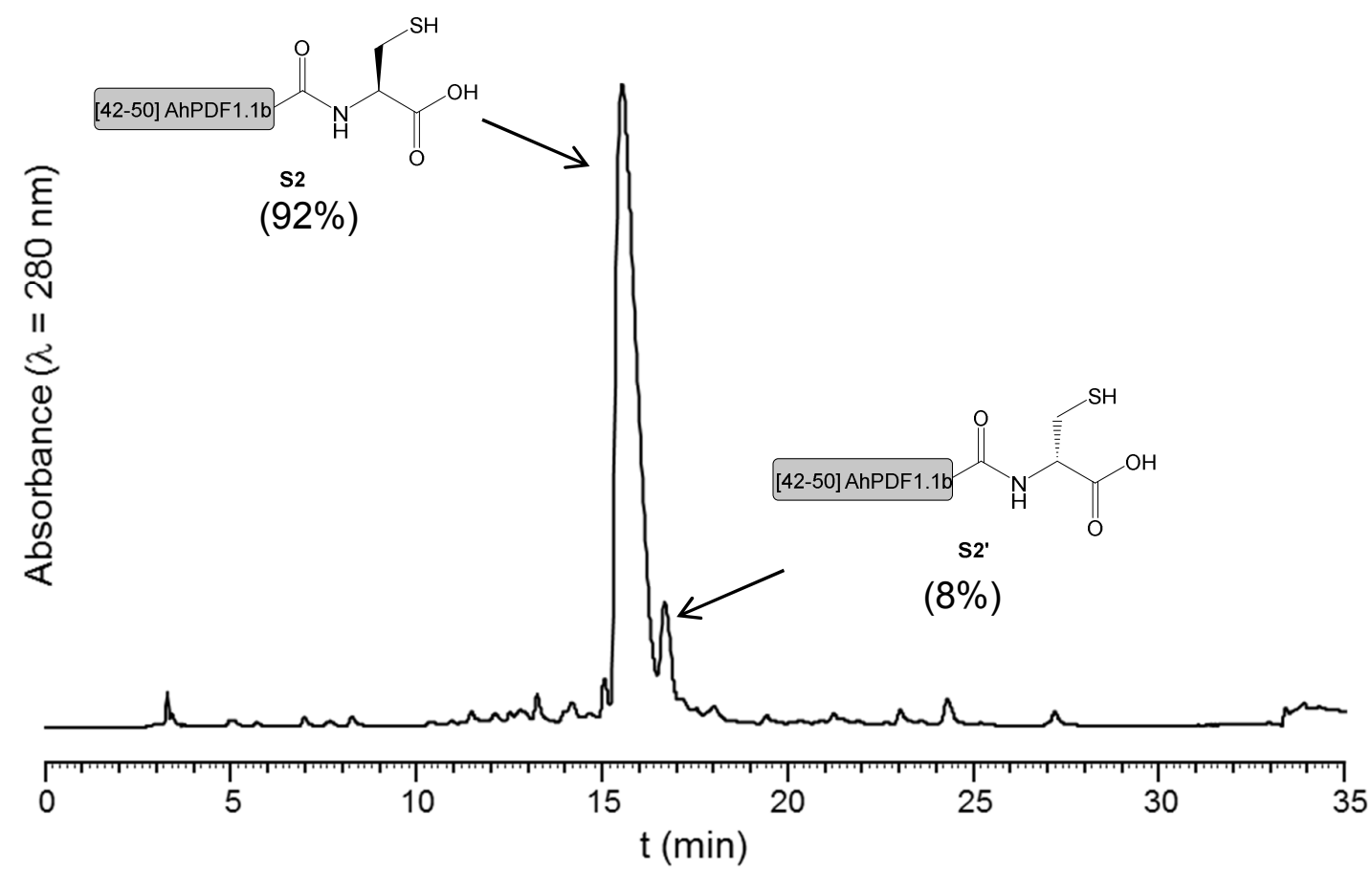

Supplementary figure S1: HPLC trace of crude $\mathbf{S 2}$ showing epimerized co-product s2'. 


\section{S3}

ESI-HRMS (m/z): [MH] $]^{+}$calcd. for $\mathrm{C}_{161} \mathrm{H}_{249} \mathrm{~N}_{50} \mathrm{O}_{41} \mathrm{~S}_{6}: 3730.7261$, found: 3730.7292 . HPLC analysis: $t_{R}=20.8$ min (Nucleosil, gradient: $20-40 \%$ B/A over 30 min).

\section{S3'}

ESI-HRMS (m/z): [MH] $]^{+}$calcd. for $\mathrm{C}_{161} \mathrm{H}_{249} \mathrm{~N}_{50} \mathrm{O}_{41} \mathrm{~S}_{6}: 3730.7261$, found: 3730.7289 . HPLC analysis: $t_{R}=21.2$ min (Nucleosil, gradient: $20-40 \%$ B/A over 30 min).

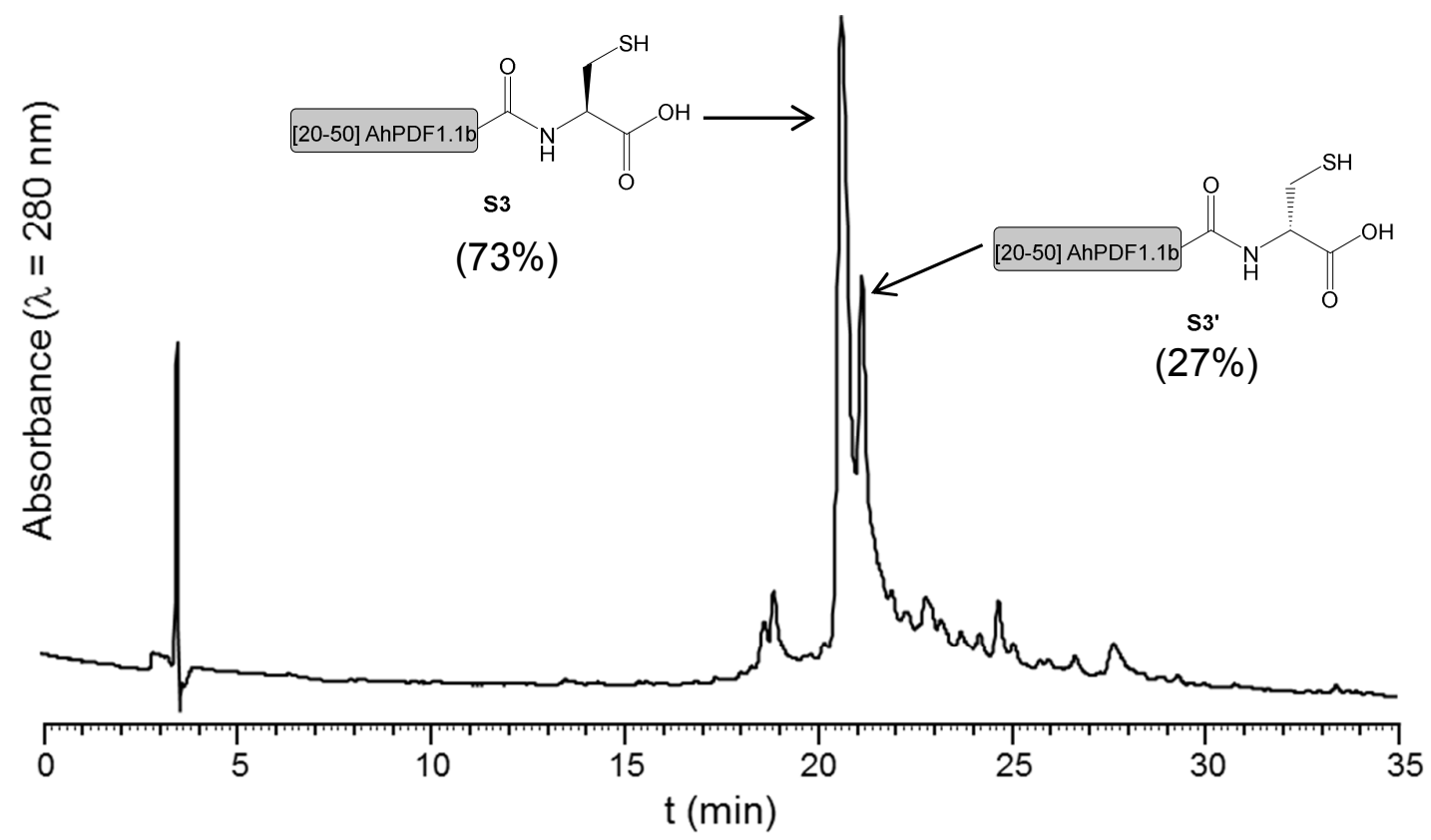

Supplementary figure S2: HPLC trace of crude $\mathbf{S 3}$ showing epimerized co-product S3'. 
After completion of [1-51] AhPDF1.1b SPPS elongation, peptide-resin was deprotected and cleaved (protocol p S3) to afford crude peptide 1 together with $32 \%$ of an isomer attributed to the epimerized co-product S1. Traces of a product consistent with piperidinylalanine formation were also observed. 1 was purified by semi-preparative RP-HPLC (Nucleosil, gradient: 28-38\% B/A over $15 \mathrm{~min}$ ) and was obtained with an overall yield of $7 \%$ (as compared to the initial loading of the $\mathrm{H}-$ Cys(Trt)-Trityl-ChemMatrix resin, and quantified by UV titration at $280 \mathrm{~mm}$ of pure 1, based on an $\varepsilon^{280}=8080 \mathrm{~L} \cdot \mathrm{mol}^{-1} \cdot \mathrm{cm}^{-1}$ in 8:2:0.01 $\mathrm{H}_{2} \mathrm{O} / \mathrm{MeCN} / \mathrm{TFA}$ ).

1

ESI-HRMS (m/z): [MH] ${ }^{+}$calcd. for $\mathrm{C}_{242} \mathrm{H}_{373} \mathrm{~N}_{76} \mathrm{O}_{68} \mathrm{~S}_{8}: 5687.5831$, found: 5687.5851 . HPLC analysis: $t_{R}=21.8 \mathrm{~min}$ (Nucleosil, gradient: $20-40 \%$ B/A over $30 \mathrm{~min}$ ).

\section{S1}

ESI-HRMS (m/z): [MH] ${ }^{+}$calcd. for $\mathrm{C}_{242} \mathrm{H}_{373} \mathrm{~N}_{76} \mathrm{O}_{68} \mathrm{~S}_{8}: 5687.5831$, found: 5687.5831 . HPLC analysis: $t_{R}=22.2$ min (Nucleosil, gradient: $20-40 \%$ B/A over $30 \mathrm{~min}$ ).

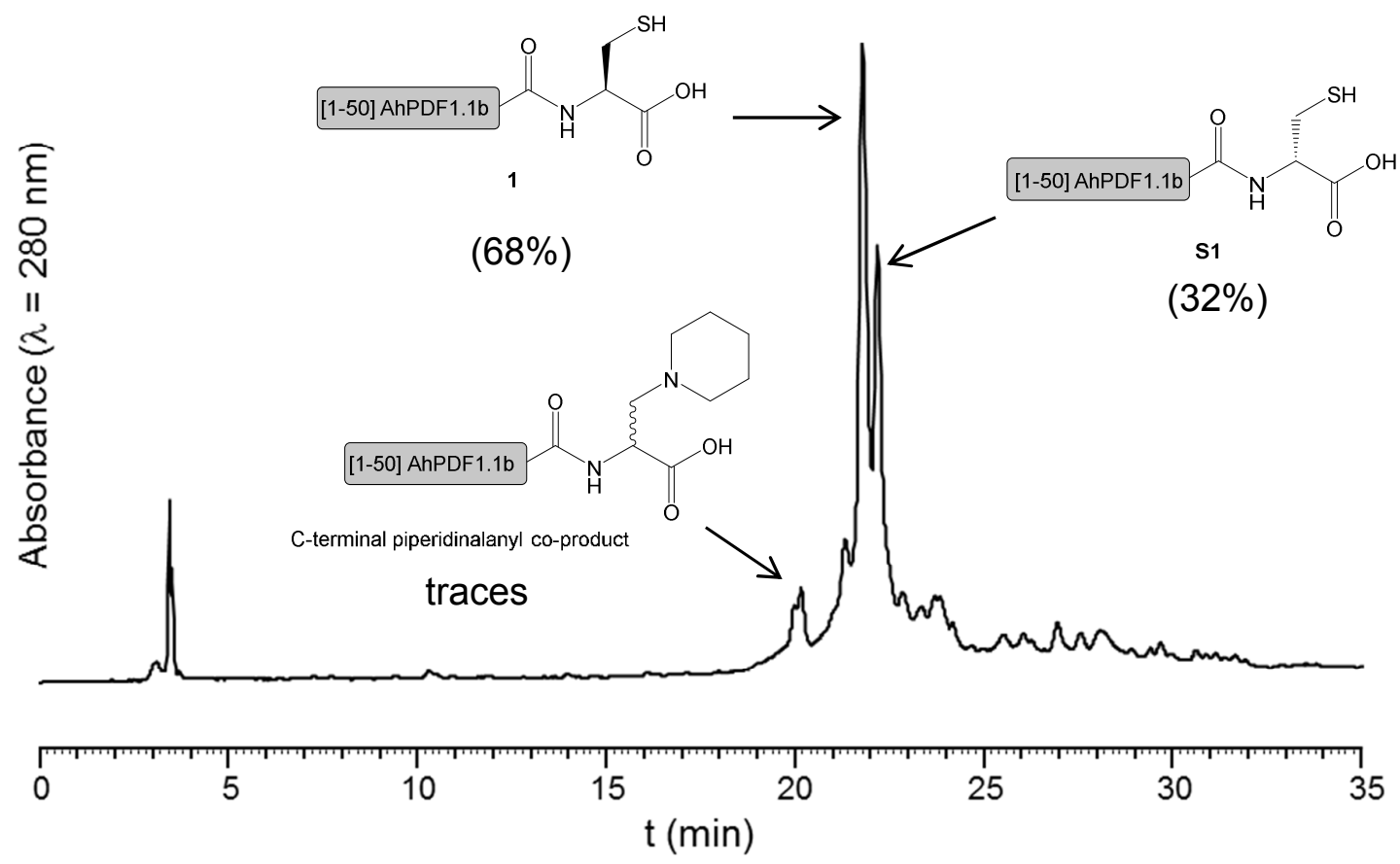

Supplementary figure S3: HPLC trace of crude 1 showing epimerized co-product S1 and traces of a minor piperidinalanyl co-product. 


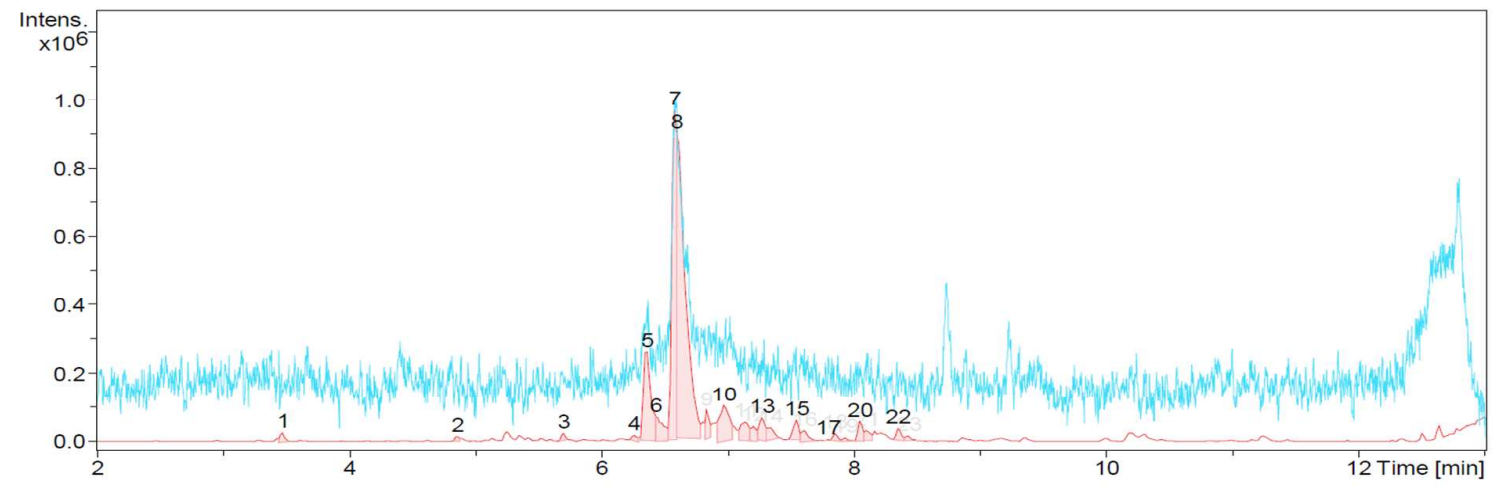

Supplementary figure S4: LC/MS analysis of crude 1. Blue trace: UV $(\lambda=214 \mathrm{~nm})$; red trace: base peak ion chromatogram.

\begin{tabular}{|c|c|c|c|}
\hline $\begin{array}{c}\text { Peak number } \\
\left(t_{R}(\min )\right)\end{array}$ & $\begin{array}{c}{[\mathrm{MH}]^{+}(\mathrm{m} / \mathrm{z})} \\
\text { calcd. }\end{array}$ & $\begin{array}{c}{[\mathrm{MH}]^{+}(\mathrm{m} / \mathrm{z})} \\
\text { found }\end{array}$ & Attributed to \\
\hline $5(6.36)$ & 5738.6845 & 5738.6878 & $\begin{array}{c}1+51 \mathrm{Da}(\mathrm{C} \text {-terminal } \\
\text { piperidinalanyl) }\end{array}$ \\
\hline $7(6.58)$ & 5687.5831 & 5687.5851 & 1 \\
\hline $8(6.60)$ & 5687.5831 & 5687.5831 & S1 (C-terminally epimerized 1) \\
\hline $10(6.97)$ & 5743.6457 & 5743.6471 & $1+56 \mathrm{Da}(t \mathrm{Bu})$ \\
\hline $13(7.27)$ & 5743.6457 & 5743.6464 & $1+56 \mathrm{Da}(t \mathrm{Bu})$ \\
\hline $15(7.54)$ & 2230.9335 & 2230.9317 & Ac-[32-51] AhPDF1.1b \\
\hline $20(8.05)$ & 2093.8746 & 2093.8743 & Ac-[33-51] AhPDF1.1b \\
\hline $22(8.35)$ & 1732.7690 & 1732.7676 & Ac-[37-51] AhPDF1.1b \\
\hline
\end{tabular}

Supplementary table S1: Attribution of the main peaks observed during LC/MS analysis of crude [1-51] AhPDF1.1b 1.

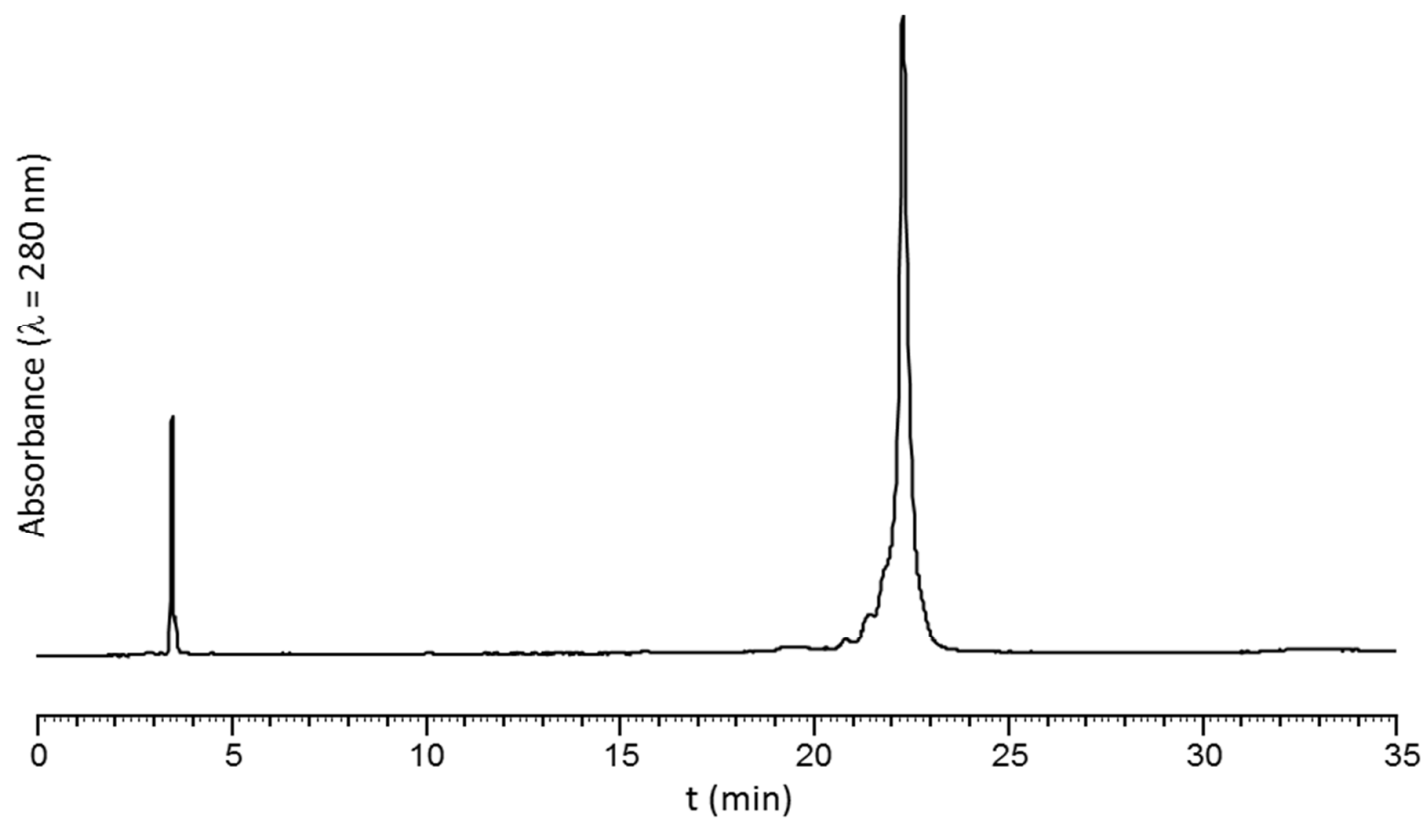

Supplementary figure S5: HPLC trace of purified 1 obtained via classical Fmoc SPPS. 


\section{Mechanistic studies on the $\mathrm{N}$-acylation of the $\mathrm{N}$-Hnb-Cys device with Fmoc-Pro-OH}

\section{4a- Preliminary results}

Consistent with our previous observations, ${ }^{2}$ the $\mathrm{N}$-acylation of the $\mathrm{N}$-Hnb-Cys device by the C-terminal Fmoc-Xaa-OH of the sequence is believed to be assisted by the hydroxyl group of $\mathrm{Hnb}$, in a similar way as the mechanism commonly admitted for peptides containing an $\mathrm{N}$-(2-hydroxy-5-methoxybenzyl) $(\mathrm{Hmb})^{3}$ or related 2hydroxybenzyl groups. ${ }^{4}$ The $\mathrm{N}$-acylation thus probably proceeds in two steps, first $\mathrm{O}$ acylation of the sterically non-hindered phenol or phenolate group of the device, followed by an intramolecular $O \rightarrow N$ acyl shift (supplementary scheme S2). In the case of sterically-hindered amino acids $(\mathrm{Xaa}=\mathrm{Val}$, Ile, $\operatorname{Thr}(\mathrm{OtBu}))$ and Pro, the $\mathrm{N}$ acylation yield obtained under standard SPPS coupling conditions are rather low, but can be dramatically enhanced by repeating the coupling step, or heating the reaction.
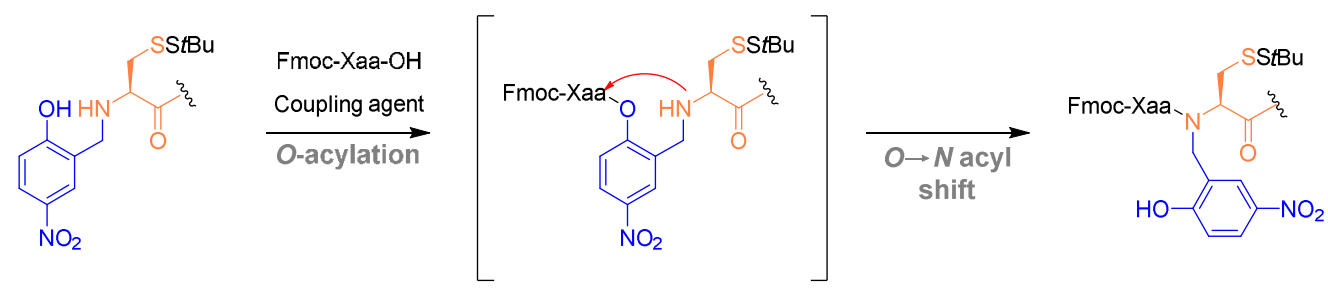

Supplementary scheme S2: Hypothetical mechanism for the $\mathrm{N}$-acylation of the HnbCys device by Fmoc-Xaa-OH.

Due to the inherent difficulties to directly monitor the solid-supported reaction, it is quite puzzling to determine whether the O-acylation or the $O \rightarrow N$ shift is the kinetically limiting step of the process. Considering previous studies by Alewood and co-workers on 2-hydroxy-5-nitrobenzyl or 2-hydroxy-6-nitrobenzyl groups as $\mathrm{N}$ substituents of $\mathrm{N}$-terminal amino acids ${ }^{4}$ of peptide sequences, we initially speculated that the $O \rightarrow N$ shift should probably be fast, due to the electron-withdrawing properties of the nitro group, making Hnb a good leaving group.

However during preliminary studies (not shown), we observed the acetic anhydridemediated capping of unreacted secondary amine was unexpectedly difficult. Indeed, we found that very long (several hours) or repeated acetic anhydride treatments (up to tenfold) were necessary to achieve a quantitative capping with the $\mathrm{Ac}_{2} \mathrm{O} / \mathrm{HOBt} / \mathrm{DIEA} / \mathrm{DMF}$ solution we standardly use for capping during SPPS. This finding is rather counterintuitive, considering the high reactivity and low steric hindrance of acetic anhydride.

\footnotetext{
${ }^{2}$ Terrier, V. P.; Adihou, H.; Arnould, M.; Delmas A. F., Aucagne, V. Chem. Sci. 2016, 339-345.

${ }^{3}$ Johnson, T.; Quibell, M.; Owen, D.; Sheppard, R. C. J. Chem. Soc. Chem. Comm. 1993, 369-372.

${ }^{4}$ Miranda, L. P.; Meutermans, W. D.; Smythe, M. L.; Alewood, P. F. J. Org. Chem. 2000, 65, 5460-5468.
} 
We hypothesized that the $\mathrm{N}$-acetylation could be slown down by the steric hindrance around the secondary amine arising from a non-rearranged $\mathrm{O}$-acylated intermediary (supplementary scheme S3).
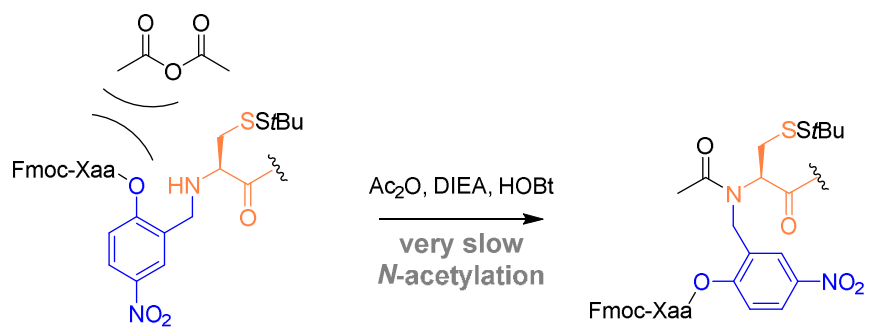

Supplementary scheme S3: Presence of non-rearranged O-acylated Hnb device as a possible explanation for the observed difficult $\mathrm{N}$-acetylation of unreacted secondary amine of the Hnb-Cys device after coupling of a sterically-hindered Fmoc-Xaa-OH.

In order to gain further insights in the $\mathrm{N}$-acylation mechanism, and help us to devise an efficient and automated capping protocol for the unreacted $\mathrm{N}$-Hnb amine, we took the occasion of the herein described application to the very demanding Pro cryptothioester $\mathbf{2}$ for exploring this specific aspect.

Considering our hypotheses based on (1) slow $O \rightarrow N$ shift and (2) steric hindrance of the secondary amine by the non-rearranged $\mathrm{O}$-acylated $\mathrm{Hnb}$, we thought of performing a few simple indirect experiments to confirm our speculations: (1) washing the resin after a 30 min standard coupling, in order to remove the excess of Fmoc-Pro activated ester, and further incubate the peptide-resin under similar conditions as the one used for the coupling but omitting Fmoc-Pro and coupling reagent (DIEA, NMP), and (2) finding conditions to selectively cleave the Hnb ester, in order to probe the expected fast kinetics of $\mathrm{N}$-acetylation of a non-O-acylated $\mathrm{N}$ Hnb-Cys. 


\section{4b- Synthesis of $\mathrm{N}$-Hnb-Cys resin S5}

To perform this mechanistic studies, resin S5 equipped with our $\mathrm{N}$-Hnb-Cys transesterification device was first synthesized under the conditions we earlier reported (supplementary scheme S4). ${ }^{2}$

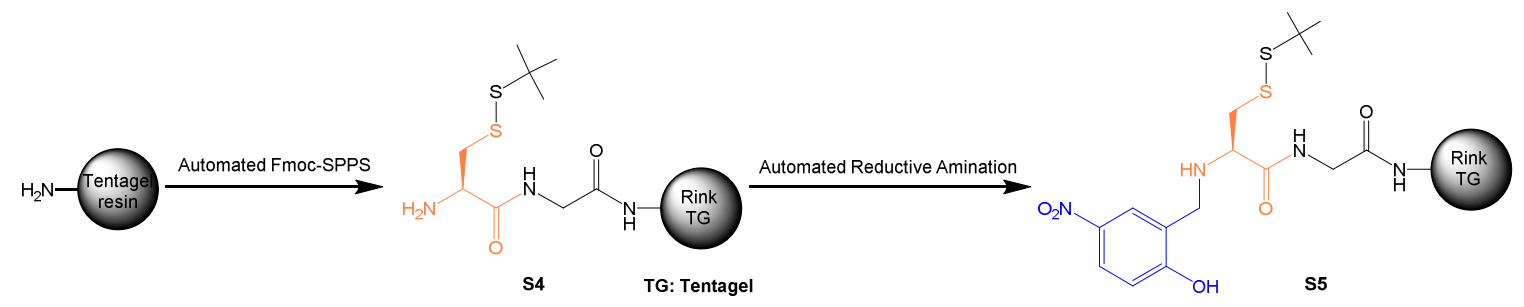

Supplementary scheme S4: Synthesis of peptide-resin S5.

The Rink's linker, Gly and Cys(StBu) were successively coupled by automated SPPS (general procedure $p \mathrm{~S} 3$ ) on a Tentagel $\mathrm{R}$ resin $(120 \mathrm{mg}, 0.21 \mathrm{mmol} / \mathrm{g}, 25 \mu \mathrm{mol})$ in order to obtain peptide-resin $\mathbf{S 4}$.

\section{$\underline{\text { Reductive amination: }}$}

Peptide-resin S4 $(25 \mu \mathrm{mol})$ was washed two times with $3 \mathrm{~mL}$ of a 1:1 DMF/MeOH mixture for $30 \mathrm{~s}$, then swollen in $3 \mathrm{~mL}$ of a 9:9:2 DMF/MeOH/AcOH mixture for $5 \mathrm{~min}$. The reactor was drained off and the resin was washed four times with $3 \mathrm{~mL}$ of a 1:1 $\mathrm{DMF} / \mathrm{MeOH}$ mixture for $30 \mathrm{~s}$. This process forms the acetic acid salt of the amine group of cysteine.

2-Hydroxy-5-nitrobenzaldehyde (HNBA) in 1:1 DMF/MeOH (125 mM, 10 equiv., 2 $\mathrm{mL}$ ) was then added, and the reactor was left for $1 \mathrm{~h}$ under stirring by nitrogen bubbling. The reactor was drained off and the resin was washed four times with $3 \mathrm{~mL}$ of 1:1 DMF/MeOH for $15 \mathrm{~s}$.

Without delay, a fresh solution of sodium cyanoborohydride in 9:9:2 $\mathrm{DMF} / \mathrm{MeOH} / \mathrm{AcOH}(250 \mathrm{mM}, 20$ equiv., $2 \mathrm{~mL}$ ) were added and the reactor was left for $1 \mathrm{~h}$ under stirring by nitrogen bubbling. The reactor was drained off and the resin was washed with 1:1 DMF/MeOH $(3 \mathrm{~mL}, 30 \mathrm{~s}, \times 4)$, NMP $(3 \mathrm{~mL}, 30 \mathrm{~s}, \times 3), 20 \%$ piperidine in NMP $(3 \mathrm{~mL}, 30 \mathrm{~s}, \times 3)$, NMP $(3 \mathrm{~mL}, 30 \mathrm{~s}, \times 3)$, dichloromethane $(5 \mathrm{~mL}$, $30 \mathrm{~s}, \times 3)$ and NMP $(3 \mathrm{~mL}, 30 \mathrm{~s}, \times 2)$. 


\section{4c- Study of the intramolecular $N \rightarrow O$ shift kinetics}

In order to study the mechanism of the $\mathrm{N}$-acylation of $\mathrm{N}$-Hnb-Cys device, Fmoc-Pro$\mathrm{OH}$ was coupled on peptide-resin S5 using standard automated coupling on the Prelude synthesizer (protocol p S3), for either $30 \mathrm{~min}, 3 \times 30 \mathrm{~min}, 90 \mathrm{~min}$ or $18 \mathrm{~h}$. Without delay, peptide-resins were treated with piperidine, in order to remove the Fmoc group while also cleaving any eventual $O$-acylated intermediary. Alternatively, before the piperidine treatment, peptide-resin was incubated with 20 equiv. $\operatorname{Pr}_{2} \mathrm{NEt}$ in NMP for $24 \mathrm{~h}$.

This was followed by a $2 \mathrm{~h}$ TFA treatment (TFA/ $\mathrm{H}_{2} \mathrm{O} / \mathrm{iPr}_{3} \mathrm{SiH}$ 93:5:2) to cleave the Rink's amide linker, leading to a mixture of $\mathrm{N}$-acylated H-Pro-(Hnb)Cys(StBu)-Gly$\mathrm{NH}_{2}$ (S6) and non-acylated $\mathrm{H}$-(Hnb)Cys(StBu)-Gly-NH $\mathrm{H}_{2}$ (S7) (scheme S5). After evaporation of TFA, the samples were analyzed by HPLC; the $\mathrm{N}$-acylation yields were quantified by integration at $315 \mathrm{~nm}$, taking into account the molar extinction coefficients of $\mathbf{S 6}$ and $\mathbf{S 7}$ (table S2).
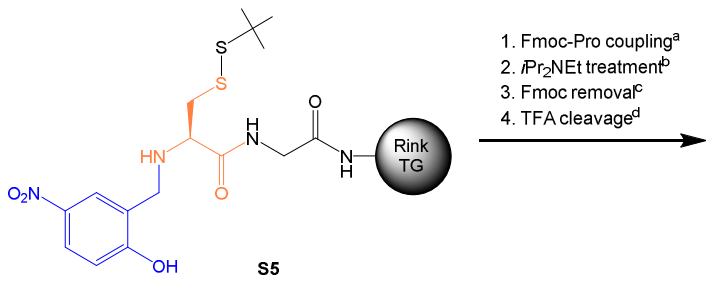

a) Fmoc-Pro-OH (10 equiv.), HCTU (9 equiv.), DIEA (20 equiv.), NMP.

b) $\mathrm{Pr}_{2} \mathrm{NEt}$ (20 equiv.), NMP

c) Piperidine $20 \%$, NMP, $3 \times 3 \mathrm{~min}$.

d) $\mathrm{TFA} / \mathrm{H}_{2} \mathrm{O} / \mathrm{TIS} 93: 5: 2,2 \mathrm{~h}$.

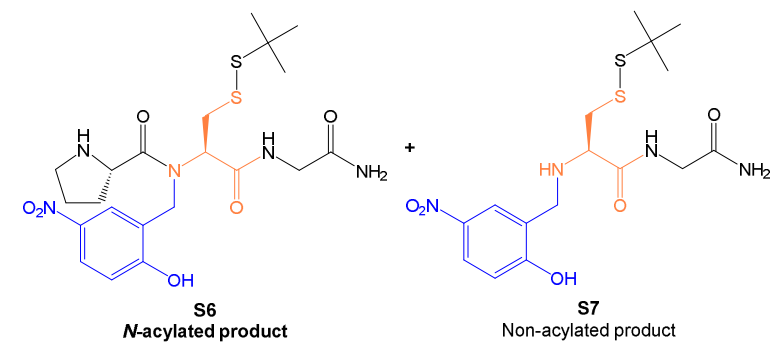

Supplementary scheme S5: Studies of the coupling of Fmoc-Pro-OH on S5.

\begin{tabular}{|c|c|c|c|c|c|}
\hline Coupling time (h) & 0.5 & $0.5 \times 3$ & 1.5 & 0.5 & 18 \\
\hline $\begin{array}{c}\text { iPr } \mathrm{Pr}_{2} \mathrm{NEt} \text { treatment } \\
\text { time (h) }\end{array}$ & 0 & 0 & 0 & 24 & 0 \\
\hline $\mathrm{N}$-acylation (\%) & 17 & 33 & 34 & 62 & 95 \\
\hline
\end{tabular}

Supplementary table S2: $\mathrm{N}$-acylation yield of peptide-resin S5 with coupling of FmocPro- $\mathrm{OH}$, eventually followed by a $24 \mathrm{~h}$ incubation with $\mathrm{PP}_{2} \mathrm{NEt}$ in NMP.

These results are in perfect accordance with a slow $O \rightarrow N$ shift hypothesis: indeed, a $24 \mathrm{~h}$ hour incubation after thorough wash of the resin after a 30 min coupling led to a good $62 \%$ yield, to be compared with a $17 \%$ yield with no extra treatment with $\mathrm{PPr}_{2} \mathrm{NEt}$ in NMP. Note that the $\mathrm{O}$-acylation is probably relatively slow, and not quantitative after $30 \mathrm{~min}$ : threefold coupling for $30 \mathrm{~min}$ or $90 \mathrm{~min}$ coupling doubled the $N$-acylation yield. Overnight reaction leads to an excellent $95 \%$ yield. 


\section{4d-Selective cleavage of the Hnb esters}

We thought that a simple way to selectively cleave the Hnb esters without affecting the integrity of the Fmoc protective group could rely on a treatment with a nucleophile under moderately basic conditions. Inspired by conditions developed by Bradley et al. for the selective nucleophilic cleavage of a Dde group versus a $N$-Fmoc group, ${ }^{5}$ we found that a solution of hydroxylamine hydrochloride $(0.3 \mathrm{M})$ and imidazole $(0.225 \mathrm{M})$ in a $\mathrm{NMP} / \mathrm{CH}_{2} \mathrm{Cl}_{2}$ mixture (5:1) cleanly cleaved any $\mathrm{Hnb}$ ester present (supplementary scheme S6). Conveniently, this process could be monitored by UV spectrometry of the Fmoc-Pro-NHOH product at $301 \mathrm{~nm}$. We found that two $20 \mathrm{~min}$ treatments resulted in complete cleavage of Hnb esters. Importantly, we found that performing the capping step after this treatment resulted in very fast $\mathrm{N}$-acetylation of the non-acylated secondary amines, supporting our initial hypothesis of slow capping caused by the steric hindrance of a non-rearranged Hnb ester.

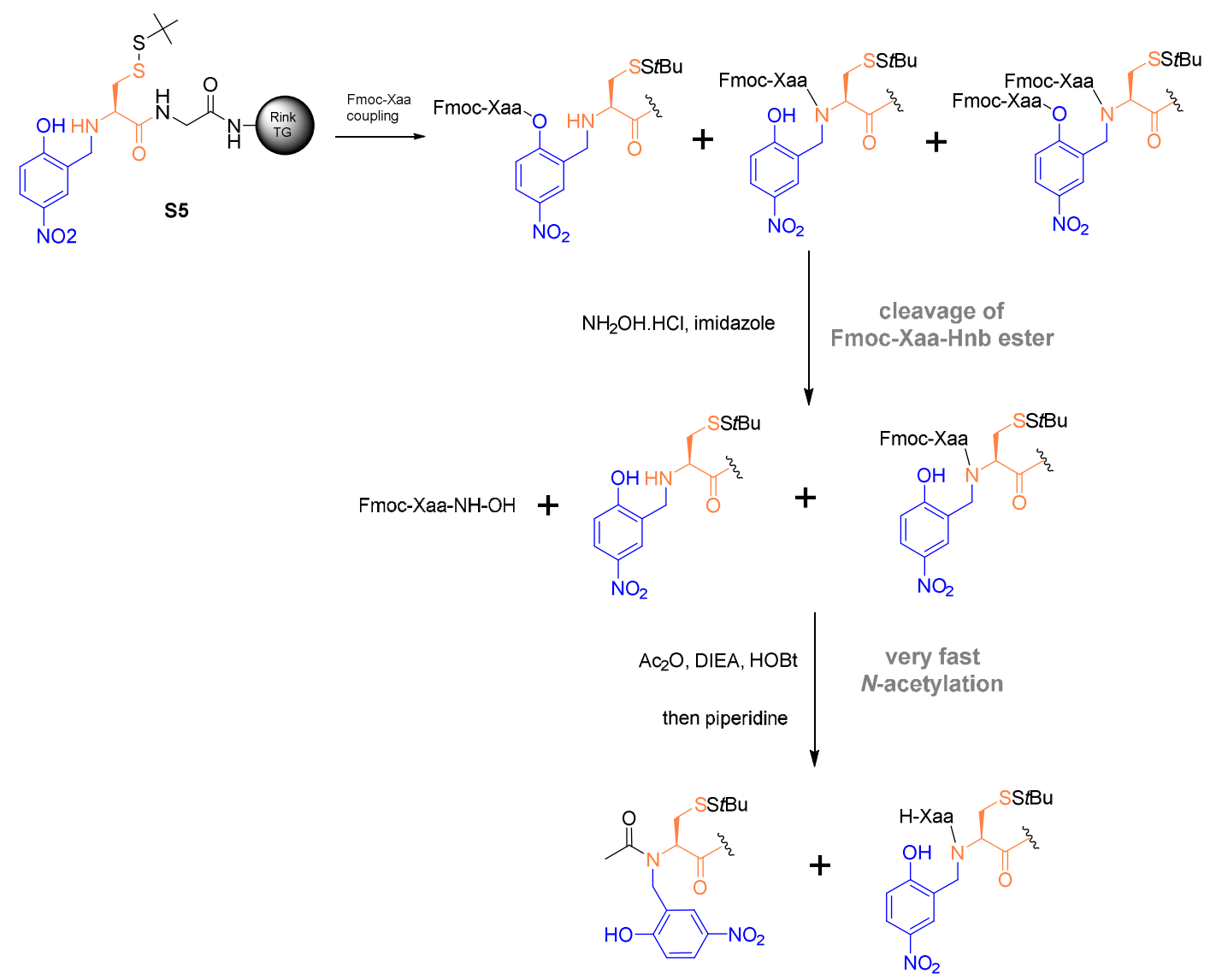

Supplementary scheme S6: Nucleophile-mediated cleavage of a putative $\mathrm{O}-\mathrm{Hnb}$ ester prior to the $\mathrm{N}$-acetylation of the $\mathrm{Hnb}-\mathrm{Cys}$ device after coupling of a Fmoc-Xaa-OH.

\footnotetext{
${ }^{5}$ Diaz-Mochon, J. J.; Bialy, L.; Bradley, M. Org. Lett., 2004, 6, 1127-1129.
} 
All together, these results strongly supports that, at least in the case of Pro, the $\mathrm{N}$ acylation process is limited by a slow $O \rightarrow N$ acyl shift (see supplementary scheme S7).

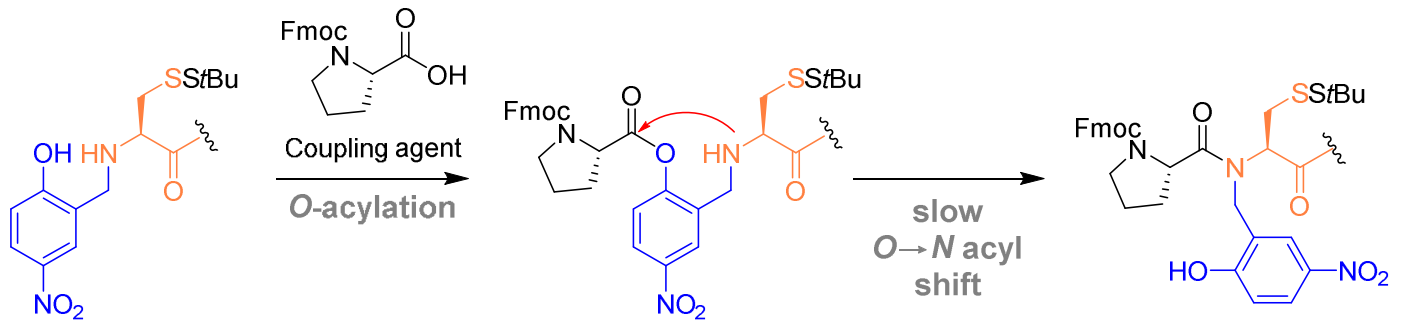

Supplementary scheme S7: Mechanism of $N$-acylation of the Hnb-Cys device by Fmoc-Pro-OH. 


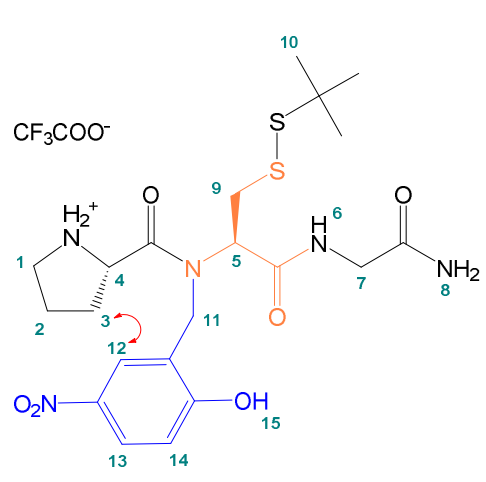

Trans conformer of $\mathrm{S} 6$

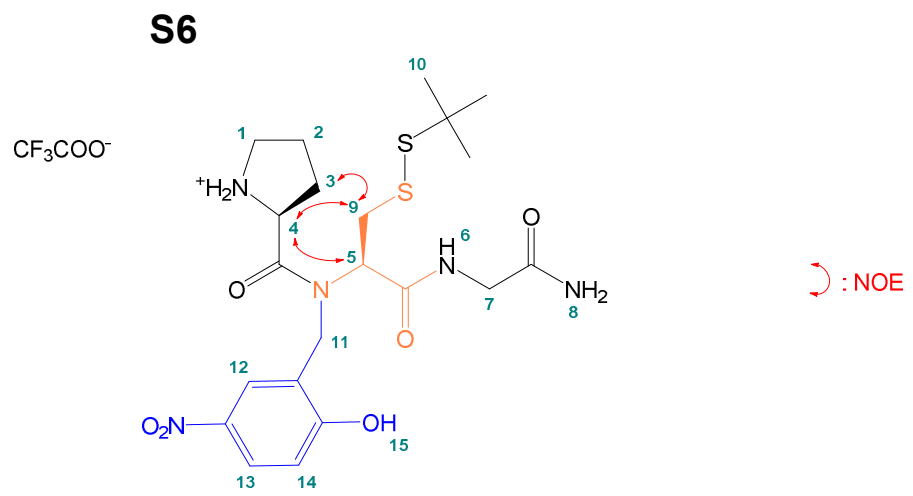

Cis conformer of $\mathrm{S} 6$

For characterization purposes, $\mathbf{S 6}$ was prepared and isolated as follows: Fmoc-Pro$\mathrm{OH}$ was coupled on peptide-resin $\mathbf{S 5}(0.1 \mathrm{mmol})$ for $18 \mathrm{~h}$ using standard automated coupling on the Prelude synthesizer (protocol p S3). Without delay, peptide-resin was treated with piperidine (protocol p S3), then cleaved through a $2 \mathrm{~h} T F A / \mathrm{H}_{2} \mathrm{O} / \mathrm{iPr}_{3} \mathrm{SiH}$ 93:5:2 treatment. After evaporation of TFA under reduced pressure, the crude mixture was purified by semi-preparative RP-HPLC (Nucleosil, gradient: $35-39 \%$ B/A over $12 \mathrm{~min}$ ) then lyophilized to yield pure $\mathbf{S 6}$ as an amorphous white fluffy solid (20.5 mg, 33\%) (yield not optimized: as this experiment was dedicated to characterize a high purity material, only the top of the HPLC peak was collected).

As expected from probable slow cis-trans isomerization of $\mathbf{S 6}$ at room temperature, its ${ }^{1} \mathrm{H}$ and ${ }^{13} \mathrm{C}$ NMR spectra at $298 \mathrm{~K}$ showed two distinct sets of peaks, in a 55:45 ratio. In the following description of the ${ }^{1} \mathrm{H}$ and ${ }^{13} \mathrm{C}$ data, the respective major $(55 \%)$ and minor $(45 \%)$ signals from both conformers are annotated as $M$ and $m$, respectively. Most of the signals were clearly discernable, and were attributed according to COSY and ${ }^{1} \mathrm{H}-{ }^{13} \mathrm{C} \mathrm{HSQC} \mathrm{2D} \mathrm{spectra,} \mathrm{or} \mathrm{relative} \mathrm{peaks} \mathrm{height} \mathrm{for}$ quaternary ${ }^{13} \mathrm{C}$ signals.

Based on 2D ${ }^{1} \mathrm{H}$ NMR ROESY experiments, the major form was attributed to the cis conformer, as strong $\mathrm{H}_{3 a}-\mathrm{H}_{9}, \mathrm{H}_{4}-\mathrm{H}_{5}$ and $\mathrm{H}_{4}-\mathrm{H}_{9} \mathrm{NOE}$ were observed for this set of proton signals, while no correlations between $\mathrm{H}_{3 a}$ or $\mathrm{H}_{4}$, and $\mathrm{H}_{11 \mathrm{a} / \mathrm{b}}$ or $\mathrm{H}_{12}$ could be detected.

Moreover, in the case of the minor isomer, weak $\mathrm{NOE}$ between $\mathrm{H}_{3 a}$ and $\mathrm{H}_{12}$ were observed and no NOE between $\mathrm{H}_{3 a}$ and $\mathrm{H}_{9}$ could be detected, fully consistent with a trans conformation. Note that no conclusive NOE correlations could be obtained for the minor isomer, due to undiscernible ${ }^{1} \mathrm{H}$ NMR signals for $\mathrm{H}_{11 \mathrm{a}, \mathrm{b}}$ and $\mathrm{H}_{4}$, precluding the unambiguous observation of $\mathrm{H}_{3}-\mathrm{H}_{4}$ correlations towards $\mathrm{H}_{3}-\mathrm{H}_{11}$.

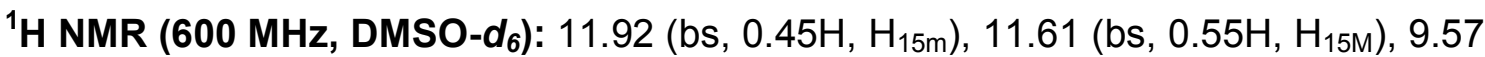
(bs, $\left.1 \mathrm{H}, \mathrm{NH}_{2}{ }^{+}\right), 8.71\left(\mathrm{t}, 0.55 \mathrm{H}, J=5.5 \mathrm{~Hz}, \mathrm{H}_{6 \mathrm{M}}\right), 8.65$ (bs, $\left.1 \mathrm{H}, \mathrm{NH}_{2}{ }^{+}\right), 8.19(\mathrm{~d}, 0.45 \mathrm{H}, J$ $\left.=2.8 \mathrm{~Hz}, \mathrm{H}_{12 \mathrm{~m}}\right), 8.09-8.15\left(\mathrm{~m}, 0.9 \mathrm{H}, \mathrm{H}_{6 \mathrm{~m}}\right.$ and $\left.\mathrm{H}_{13 \mathrm{~m}}\right), 8.02(\mathrm{dd}, 0.55 \mathrm{H}, \mathrm{J}=8.9,2.8 \mathrm{~Hz}$, $\left.\mathrm{H}_{13 \mathrm{M}}\right), 7.83\left(\mathrm{~d}, 0.55 \mathrm{H}, J=2.8 \mathrm{~Hz}, \mathrm{H}_{12 \mathrm{M}}\right), 7.38$ (bs, $\left.0.55 \mathrm{H}, \mathrm{H}_{8 \mathrm{aM}}\right), 7.21$ (bs, $0.45 \mathrm{H}$, $\mathrm{H}_{8 \mathrm{am}}$ ), 7.13 (bs, $0.55 \mathrm{H}, \mathrm{H}_{8 \mathrm{bM}}$ ), 7.08 (bs, $\left.0.45 \mathrm{H}, \mathrm{H}_{8 \mathrm{bm}}\right), 7.05$ (d, $0.45 \mathrm{H}, J=8.9 \mathrm{~Hz}$, $\left.\mathrm{H}_{14 \mathrm{~m}}\right), 6.99\left(\mathrm{~d}, 0.55 \mathrm{H}, J=8.9 \mathrm{~Hz}, \mathrm{H}_{14 \mathrm{M}}\right), 4.90-4.97\left(\mathrm{~m}, 0.55 \mathrm{H}, \mathrm{H}_{4 \mathrm{M}}\right), 4.85(\mathrm{dd}, 0.55 \mathrm{H}, J$ $\left.=7.1,7.1 \mathrm{~Hz}, \mathrm{H}_{5 \mathrm{M}}\right), 4.73\left(\mathrm{dd}, 0.45 \mathrm{H}, J=7.1,7.1 \mathrm{~Hz}, \mathrm{H}_{5 \mathrm{~m}}\right), 4.63-4.72\left(\mathrm{~m}, 1.35 \mathrm{H}, \mathrm{H}_{4 \mathrm{~m}}\right.$, $\mathrm{H}_{11 \mathrm{am}}$ and $\left.\mathrm{H}_{11 \mathrm{bm}}\right), 4.61\left(\mathrm{~d}, 0.55 \mathrm{H}, J=16.9 \mathrm{~Hz}, \mathrm{H}_{11 \mathrm{am}}\right), 4.52(\mathrm{~d}, 0.55 \mathrm{H}, J=16.9 \mathrm{~Hz}$, $\left.\mathrm{H}_{11 \mathrm{bM}}\right), 3.72\left(\mathrm{dd}, 0.55 \mathrm{H}, J=16.8,6.0 \mathrm{~Hz}, \mathrm{H}_{7 \mathrm{am}}\right), 3.49-3.62\left(\mathrm{~m}, 1.45 \mathrm{H}, \mathrm{H}_{7 \mathrm{am}}, \mathrm{H}_{7 \mathrm{bm}}\right.$ and $\left.\mathrm{H}_{7 \mathrm{bM}}\right), 3.15-3.39\left(\mathrm{~m}, 3 \mathrm{H}, \mathrm{H}_{1 \mathrm{am}}, \mathrm{H}_{1 \mathrm{bm}}, \mathrm{H}_{1 \mathrm{am}}, \mathrm{H}_{1 \mathrm{bM}}, \mathrm{H}_{9 \mathrm{am}}\right.$ and $\left.\mathrm{H}_{9 \mathrm{M}}\right), 3.01(\mathrm{dd}, 0.55 \mathrm{H}, \mathrm{J}=$ 
13.7, 7.6 Hz, $\mathrm{H}_{9 \mathrm{bm}}$ ), 2.84 (dd, 0.45H, J = 13.2, 7.3 Hz, $\left.\mathrm{H}_{9 b m}\right), 2.60-2.67(\mathrm{~m}, 0.55 \mathrm{H}$, $\mathrm{H}_{3 \mathrm{am}}$ ), 2.33-2.42 (m, 0.45H, $\left.\mathrm{H}_{3 \mathrm{am}}\right), 1.88-2.08\left(\mathrm{~m}, 3 \mathrm{H}, \mathrm{H}_{2 \mathrm{am}}, \mathrm{H}_{2 \mathrm{bm}}, \mathrm{H}_{2 \mathrm{am}}, \mathrm{H}_{2 \mathrm{bm}}, \mathrm{H}_{3 \mathrm{bm}}\right.$ and $\left.\mathrm{H}_{3 \mathrm{bM}}\right), 1.21\left(\mathrm{~s}, 9 \mathrm{H}, \mathrm{H}_{10 \mathrm{~m}}\right.$ and $\mathrm{H}_{10 \mathrm{M}}$ ).

${ }^{13} \mathrm{C}$ NMR (150 MHz, DMSO- $d_{6}$ ): $170.5 \mathrm{C}_{\mathrm{M}}, 170.1 \mathrm{C}_{\mathrm{M}}, 170.1 \mathrm{C}_{\mathrm{m}}, 170.0 \mathrm{C}_{\mathrm{m}}, 167.7 \mathrm{C}_{\mathrm{m}}$, $167.7 \mathrm{C}_{\mathrm{M}}, 162.1 \mathrm{C}_{\mathrm{m}}, 160.9 \mathrm{C}_{\mathrm{M}}, 158.1 \mathrm{COCF}_{3}\left(\mathrm{q}, \mathrm{J}_{2} \mathrm{C}-\mathrm{F}=32 \mathrm{~Hz}\right), 139.4 \mathrm{C}_{\mathrm{m}}, 139.3 \mathrm{C}_{\mathrm{M}}$, 125.7 $\mathrm{C}_{\mathrm{M}}, 125.6 \mathrm{CH}_{\mathrm{m}}, 124.6 \mathrm{CH}_{\mathrm{M}}, 124.3 \mathrm{C}_{\mathrm{m}}, 123.5 \mathrm{CH}_{\mathrm{M}}, 123.3 \mathrm{CH}_{\mathrm{m}}, 117.1 \mathrm{CF}_{3} \mathrm{CO}$ (q, $\left.J_{1 C-F}=300 \mathrm{~Hz}\right), 115.5 \mathrm{CH}_{\mathrm{m}}, 115.1 \mathrm{CH}_{\mathrm{M}}, 59.3 \mathrm{CH}_{\mathrm{m}}, 59.2 \mathrm{CH}_{\mathrm{M}}, 58.4 \mathrm{CH}_{\mathrm{M}}, 58.1 \mathrm{CH}_{\mathrm{m}}$, $48.1 \mathrm{C}_{\mathrm{M}}, 47.7 \mathrm{C}_{\mathrm{m}}, 46.1 \mathrm{CH}_{2 \mathrm{~m}}, 46.0 \mathrm{CH}_{2 \mathrm{~m}}, 45.7 \mathrm{CH}_{2 \mathrm{M}}, 42.2 \mathrm{CH}_{2 \mathrm{M}}, 42.1 \mathrm{CH}_{2 \mathrm{~m}}, 41.5$ $\mathrm{CH}_{2 \mathrm{M}}, 40.7 \mathrm{CH}_{2 \mathrm{M}}, 40.1 \mathrm{CH}_{2 \mathrm{~m}}, 29.4 \mathrm{CH}_{3 \mathrm{~m}}, 29.4 \mathrm{CH}_{2 \mathrm{M}}, 29.3 \mathrm{CH}_{3 \mathrm{M}}, 29.0 \mathrm{CH}_{2 \mathrm{~m}}, 23.7$ $\mathrm{CH}_{2 \mathrm{~m}}, 23.7 \mathrm{CH}_{2 \mathrm{M}}$.

${ }^{19}$ F NMR (565 MHz, DMSO- $\left.d_{6}\right):-73.8$.

ESI-HRMS (m/z): $[\mathrm{MH}]^{+}$calcd. for $\mathrm{C}_{21} \mathrm{H}_{32} \mathrm{~N}_{5} \mathrm{O}_{6} \mathrm{~S}_{2}: 514.1794$, found: 514.1788 .

HPLC analysis: $t_{R}=3.86$ min (Chromolith, gradient: $20-50 \%$ B/A over 5 min).

UV/VIS $\left(8: 2: 0.01 \mathrm{H}_{2} \mathrm{O} / \mathrm{MeCN} / \mathrm{TFA}, 85 \mu \mathrm{M}\right): \lambda \max =318 \mathrm{~nm}, \varepsilon^{280}=3440 \mathrm{~L} \cdot \mathrm{mol}^{-1} \cdot \mathrm{cm}^{-1}$, $\varepsilon^{315}=8090 \mathrm{~L} \cdot \mathrm{mol}^{-1} \cdot \mathrm{cm}^{-1}, \varepsilon^{318}=8130 \mathrm{~L} \cdot \mathrm{mol}^{-1} \cdot \mathrm{cm}^{-1}$.

Note that molar extinction coefficients reported here for $\mathbf{S 6}$ substantially differ from values we reported earlier ${ }^{2}$ for a model Ac-(Hnb)Cys(StBu)Gly-OH compound ( $\lambda$ max $=320 \mathrm{~nm}, \varepsilon^{280}=2359 \mathrm{~L} \cdot \mathrm{mol}^{-1} \cdot \mathrm{cm}^{-1}, \varepsilon^{320}=6325 \mathrm{~L} \cdot \mathrm{mol}^{-1} \cdot \mathrm{cm}^{-1}$. This suggests that the UV absorption of the Hnb group could be sensitive to its environment and thus be sequence-dependent. 


\section{Copy of the ${ }^{1} \mathrm{H}$ NMR spectrum:}

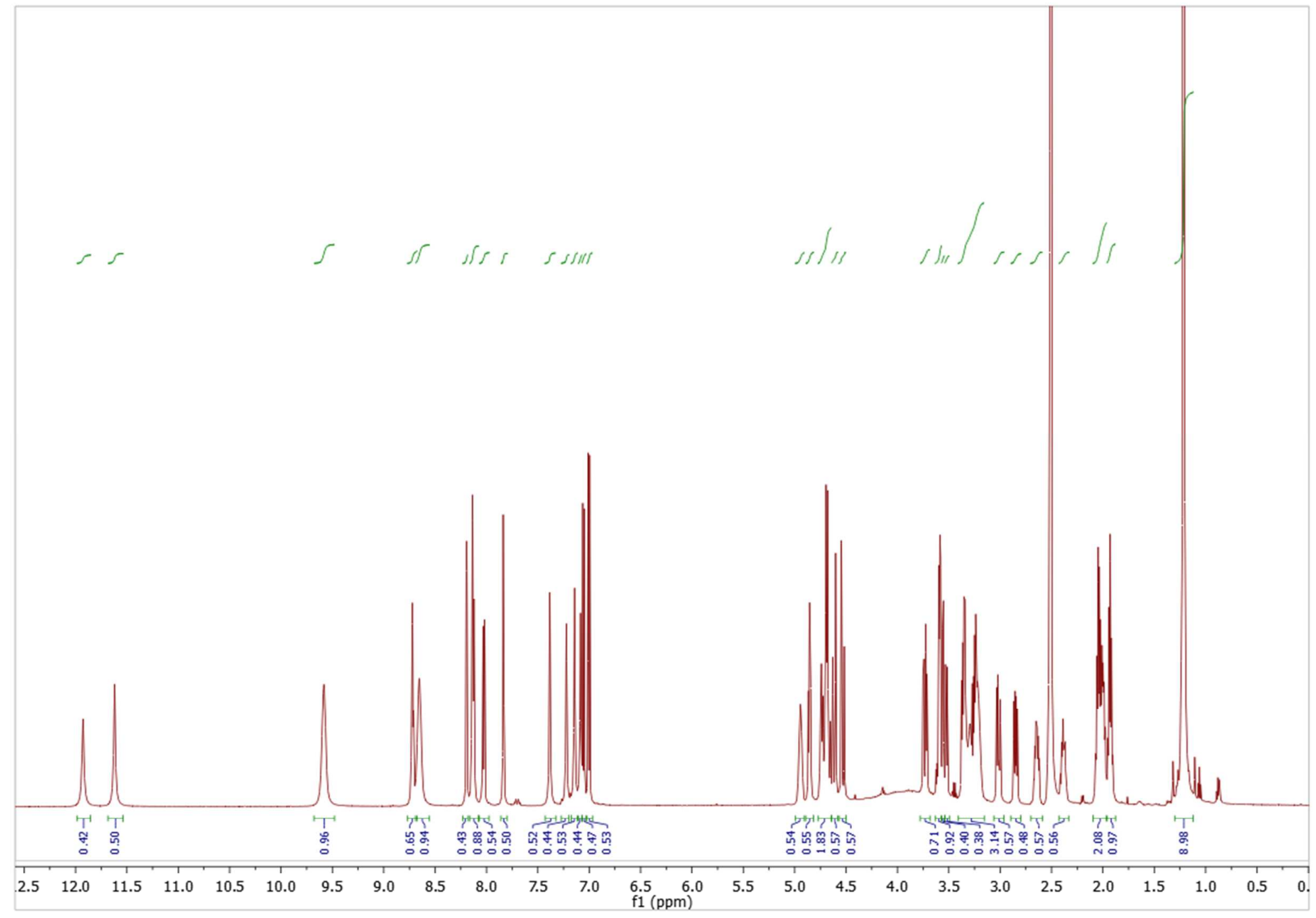

Supplementary figure S6: Copy of the ${ }^{1} \mathrm{H}$ NMR spectrum of $\mathbf{S 6}$. 


\section{Copy of the ${ }^{13} \mathrm{C}$ NMR spectrum:}

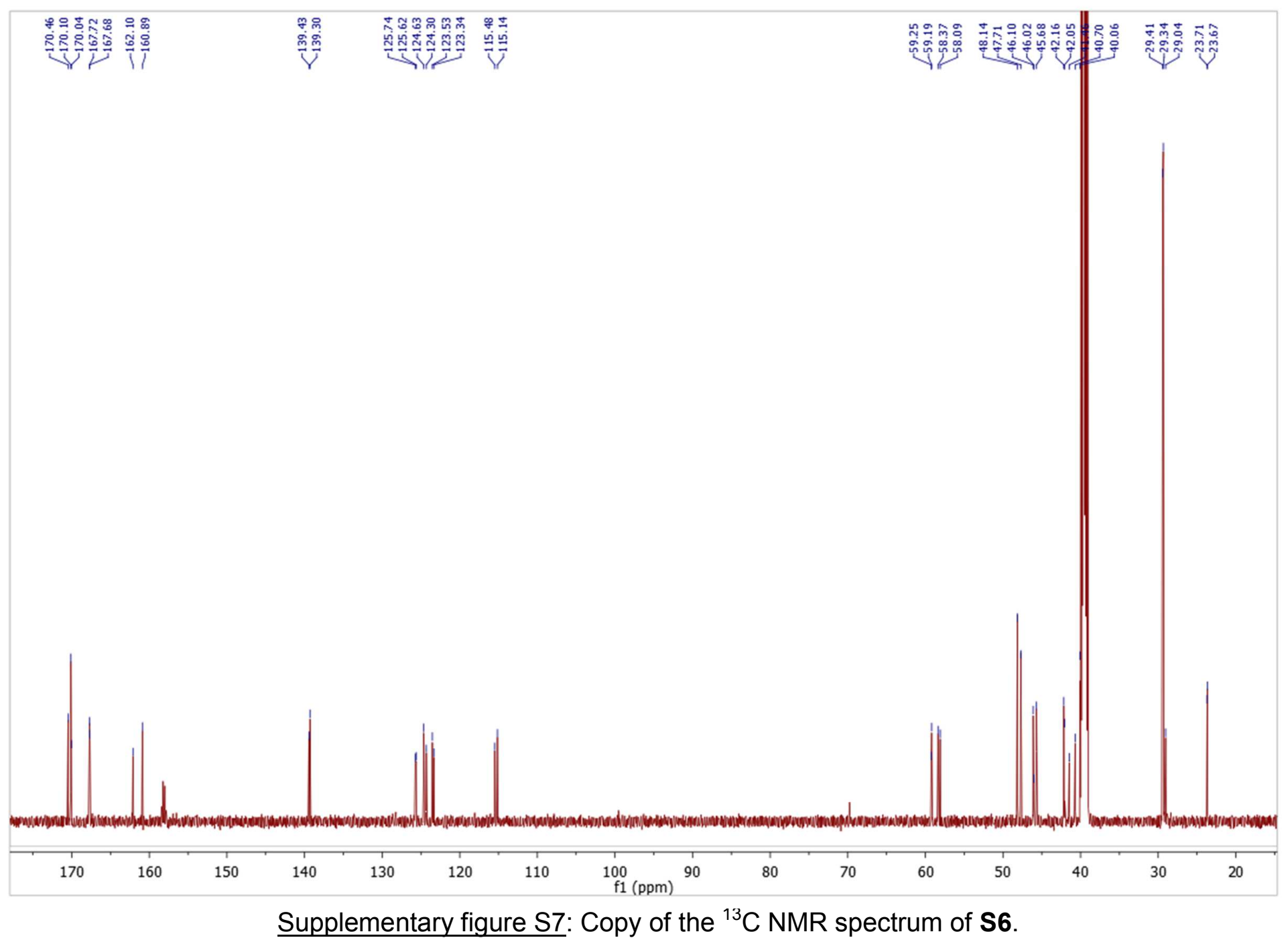




\section{Copy of the UV spectrum:}

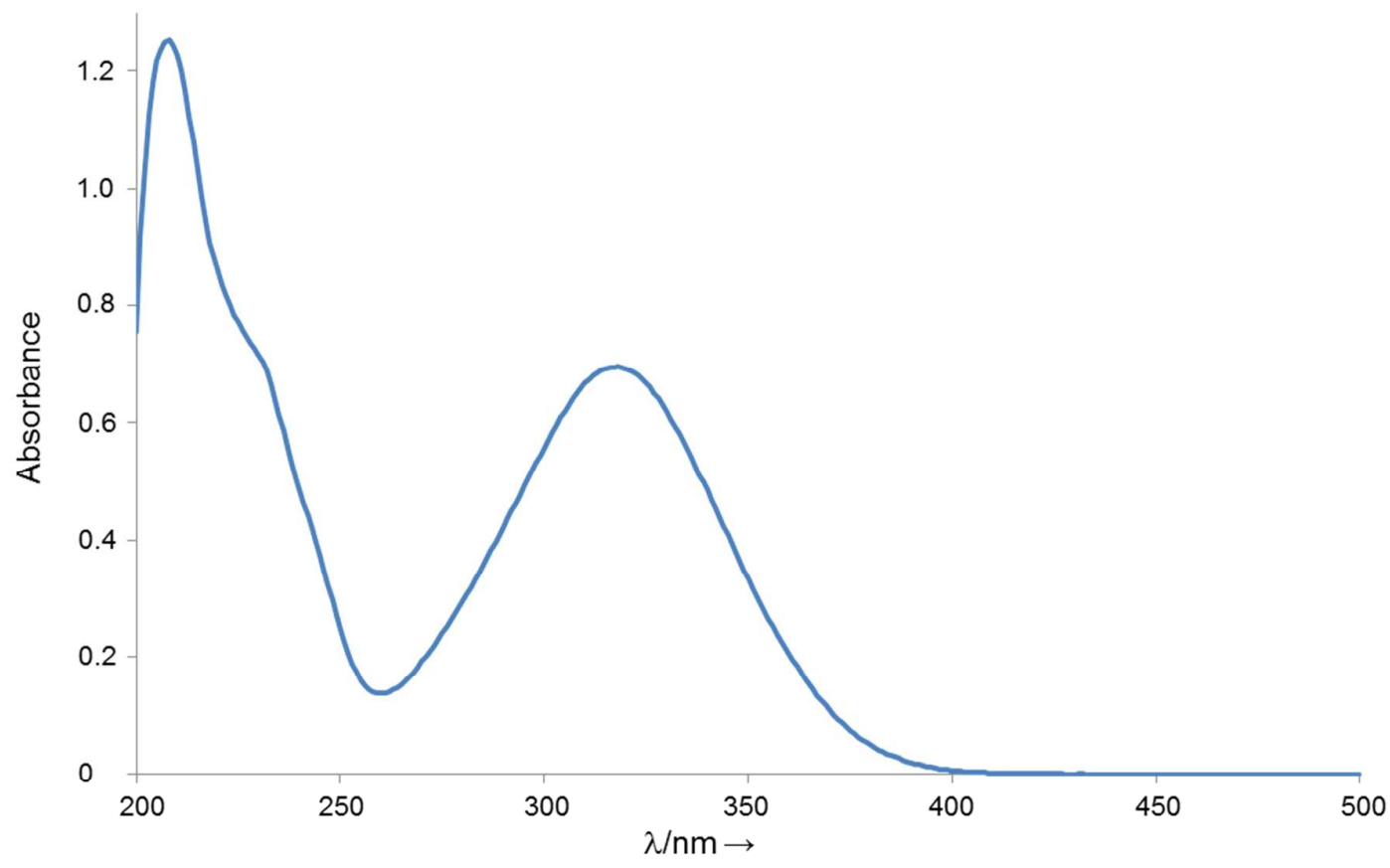

Supplementary figure S8: UV spectrum of S6.

S7

For characterization purposes, $\mathbf{S 7}$ was prepared and isolated as follows: peptideresin S5 (0.05 mmol) was cleaved through a $2 \mathrm{~h} \mathrm{TFA} / \mathrm{H}_{2} \mathrm{O} / \mathrm{iPr} \mathrm{SiH}_{3}$ 93:5:2 treatment. After evaporation of TFA under reduced pressure, the crude mixture was purified by semi-preparative RP-HPLC (Nucleosil, gradient: 26-30\% B/A over $12 \mathrm{~min}$ ) then lyophilized to yield pure $\mathbf{S 7}$ as an amorphous white fluffy solid (13 mg, 49\%) (yield not optimized: as this experiment was dedicated to characterize a high purity material, only the top of the HPLC peak was collected).

${ }^{1} \mathrm{H}$ NMR (600 MHz, DMSO-d (6) $^{2} 12.0$ (bs, $1 \mathrm{H}, \mathrm{H}_{1}$ ), 9.34 (bs, $2 \mathrm{H}, \mathrm{NH}_{2}{ }^{+}$), 8.92 (bt, $1 \mathrm{H}, J$ $\left.=5.6 \mathrm{~Hz}, \mathrm{H}_{7}\right), 8.36\left(\mathrm{~d}, 1 \mathrm{H}, J=2.8 \mathrm{~Hz}, \mathrm{H}_{4}\right), 8.18\left(\mathrm{dd}, 1 \mathrm{H}, J=9.0,2.8 \mathrm{~Hz}, \mathrm{H}_{3}\right), 7.44$ (bs, $\left.1 \mathrm{H}, \mathrm{H}_{9 \mathrm{a}}\right), 7.17$ (bs, $\left.1 \mathrm{H}, \mathrm{H}_{9 b}\right), 7.08\left(\mathrm{~d}, 1 \mathrm{H}, J=9.0 \mathrm{~Hz}, \mathrm{H}_{2}\right), 4.20(\mathrm{~d}, 1 \mathrm{H}, J=13.4$ $\left.\mathrm{Hz}, \mathrm{H}_{5 \mathrm{a}}\right), 4.16\left(\mathrm{~d}, 1 \mathrm{H}, \mathrm{J}=13.4 \mathrm{~Hz}, \mathrm{H}_{5 \mathrm{~b}}\right), 3.99-4.15\left(\mathrm{~m}, 1 \mathrm{H}, 1 \mathrm{H}, \mathrm{H}_{6}\right), 3.84(\mathrm{dd}, 1 \mathrm{H}, J=$ 16.8, $5.7 \mathrm{~Hz}, \mathrm{H}_{8 \mathrm{a}}$ ), 3.72 (dd, $1 \mathrm{H}, J=16.8,5.4 \mathrm{~Hz}, \mathrm{H}_{8 \mathrm{a}}$ ), 3.24 (dd, $1 \mathrm{H}, J=13.6,4.9 \mathrm{~Hz}$, $\mathrm{H}_{10 \mathrm{a}}$ ), 3.18 (dd, $\left.1 \mathrm{H}, \mathrm{J}=13.6,8.1 \mathrm{~Hz}, \mathrm{H}_{10 \mathrm{~b}}\right), 1.29$ (s, 9H, $\left.\mathrm{H}_{11}\right)$.

${ }^{13} \mathrm{C}$ NMR (150 MHz, DMSO-d $\left.)_{6}\right): 169.7 \mathrm{C}, 166.2 \mathrm{C}, 162.7 \mathrm{C}, 158.1 \mathrm{COCF}_{3}\left(\mathrm{q}, \mathrm{J}_{2} \mathrm{C}-\mathrm{F}=\right.$ $32 \mathrm{~Hz}$ ), $139.4 \mathrm{C}, 128.0 \mathrm{CH}, 126.7 \mathrm{CH}, 119.3 \mathrm{C}, 116.8 \mathrm{CF}_{3} \mathrm{CO}\left(\mathrm{q}, J_{1} \mathrm{C}-\mathrm{F}=305 \mathrm{~Hz}\right.$ ), 115.7 CH, 58.8 CH, 48.1 C, 43.8 $\mathrm{CH}_{2}, 42.2 \mathrm{CH}_{2}, 39.3 \mathrm{CH}_{2}, 29.4 \mathrm{CH}_{3}$.

${ }^{19}$ F NMR (565 MHz, DMSO-d $d_{6}$ ): -73.9 .

ESI-HRMS (m/z): [MH] ${ }^{+}$calcd. for $\mathrm{C}_{16} \mathrm{H}_{25} \mathrm{~N}_{4} \mathrm{O}_{5} \mathrm{~S}_{2}: 417.1266$, found: 417.1261 .

HPLC analysis: $t_{R}=2.12$ min (Chromolith, gradient: $20-50 \%$ B/A over 5 min).

UVIVIS $\left(8: 2: 0.01 \quad \mathrm{H}_{2} \mathrm{O} / \mathrm{MeCN} / \mathrm{TFA}, \quad 140 \mu \mathrm{M}\right): \lambda \max =313 \mathrm{~nm}, \quad \varepsilon^{280}=4260$ $\mathrm{L} \cdot \mathrm{mol}^{-1} \cdot \mathrm{cm}^{-1}, \varepsilon^{313}=8500 \mathrm{~L} \cdot \mathrm{mol}^{-1} \cdot \mathrm{cm}^{-1}, \varepsilon^{315}=8450 \mathrm{~L} \cdot \mathrm{mol}^{-1} \cdot \mathrm{cm}^{-1}$. 


\section{Copy of the ${ }^{1} \mathrm{H}$ NMR spectrum:}

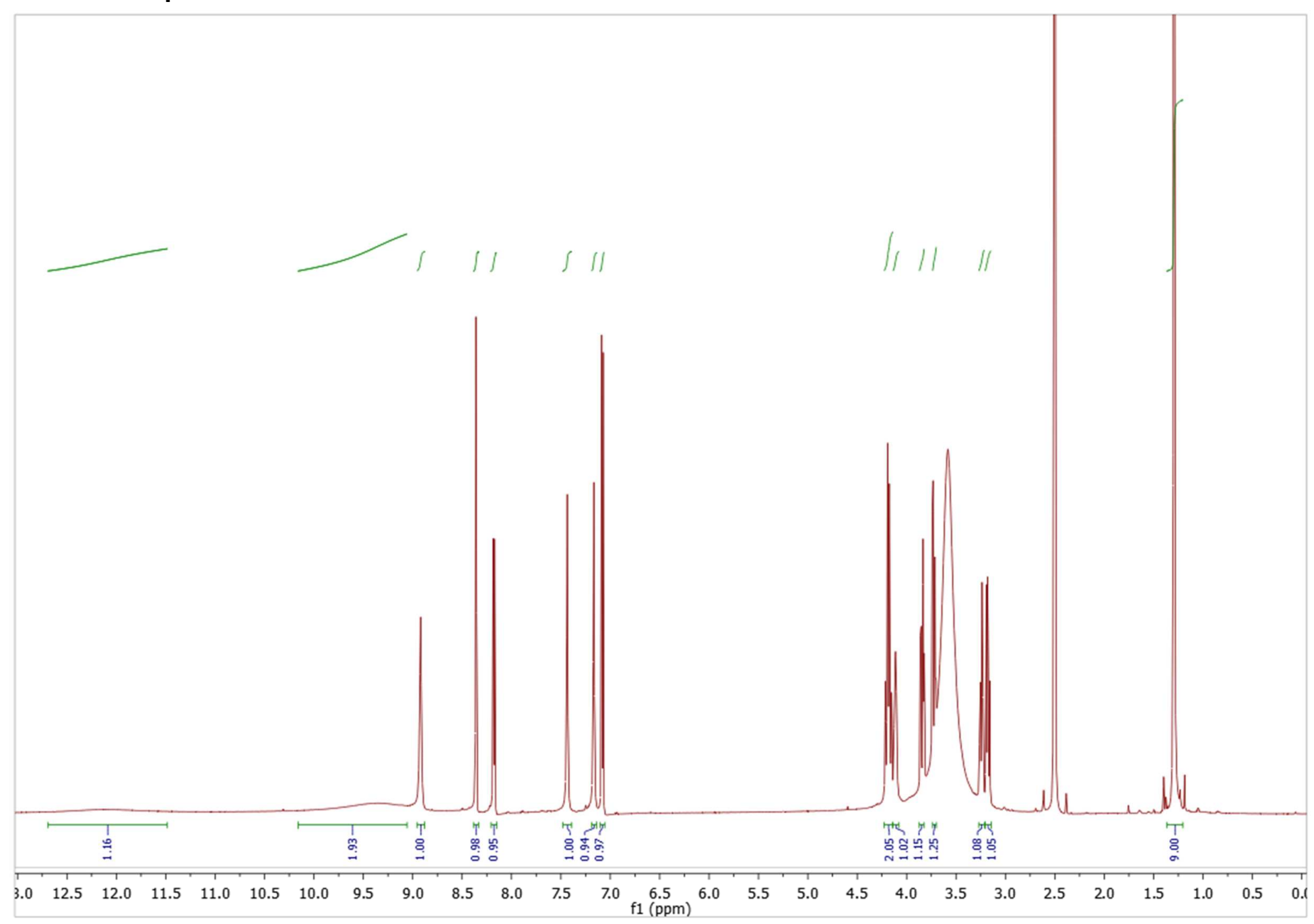

Supplementary figure S9: Copy of the ${ }^{1} \mathrm{H}$ NMR spectrum of $\mathbf{S 7}$. 


\section{Copy of the ${ }^{13} \mathrm{C}$ NMR spectrum:}

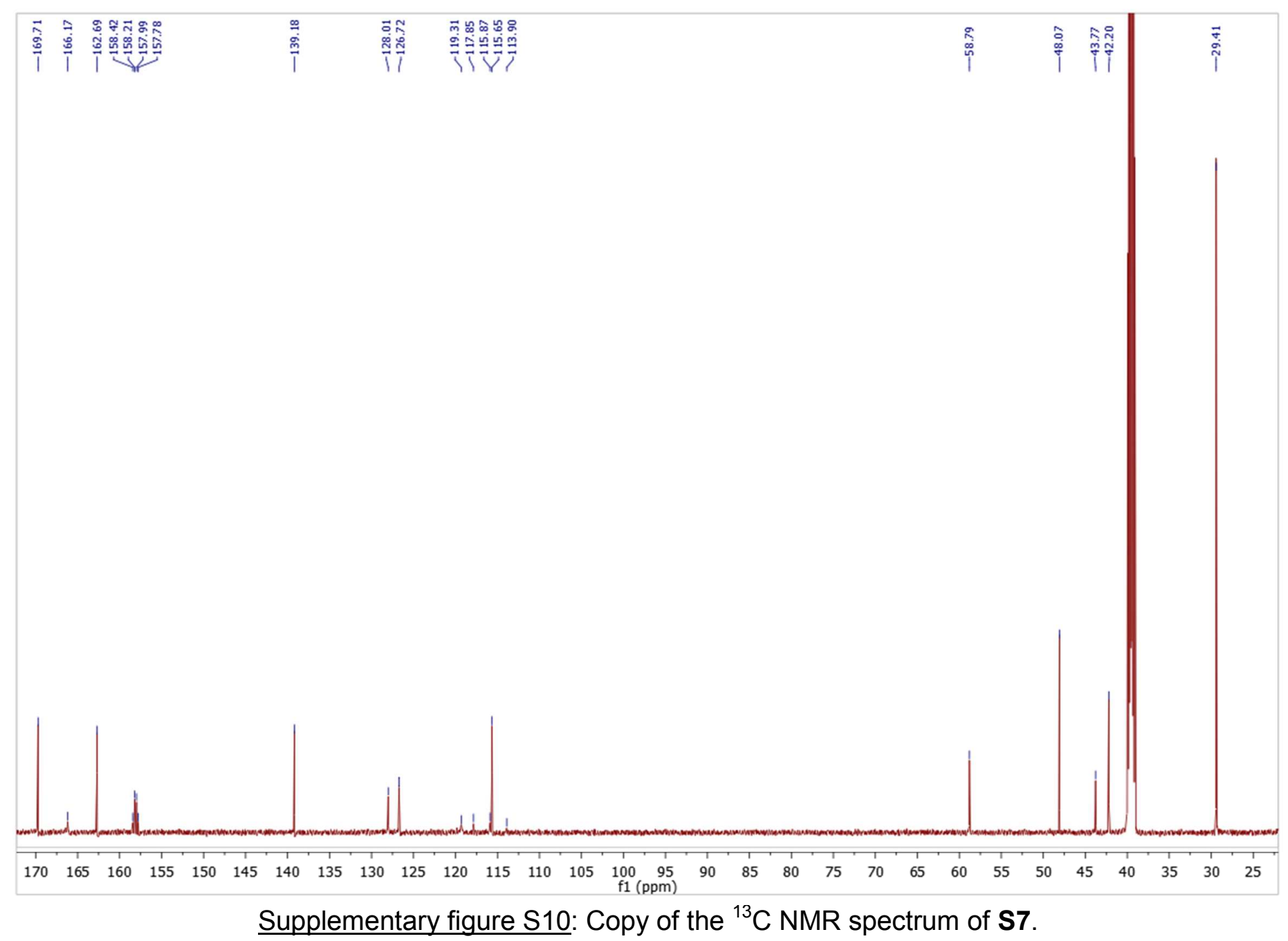




\section{Copy of the UV spectrum:}

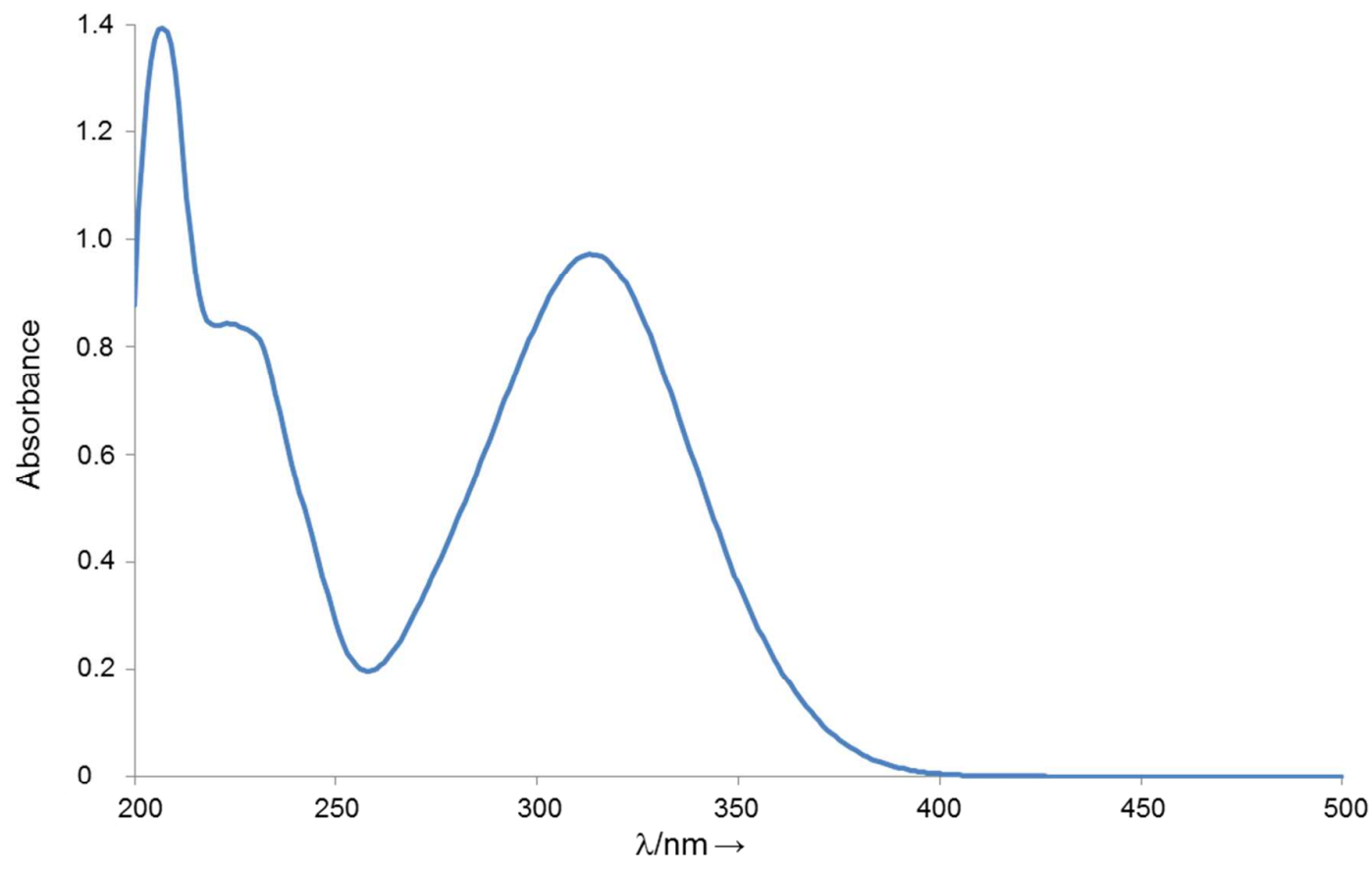

Supplementary figure S11: UV spectrum of S7. 


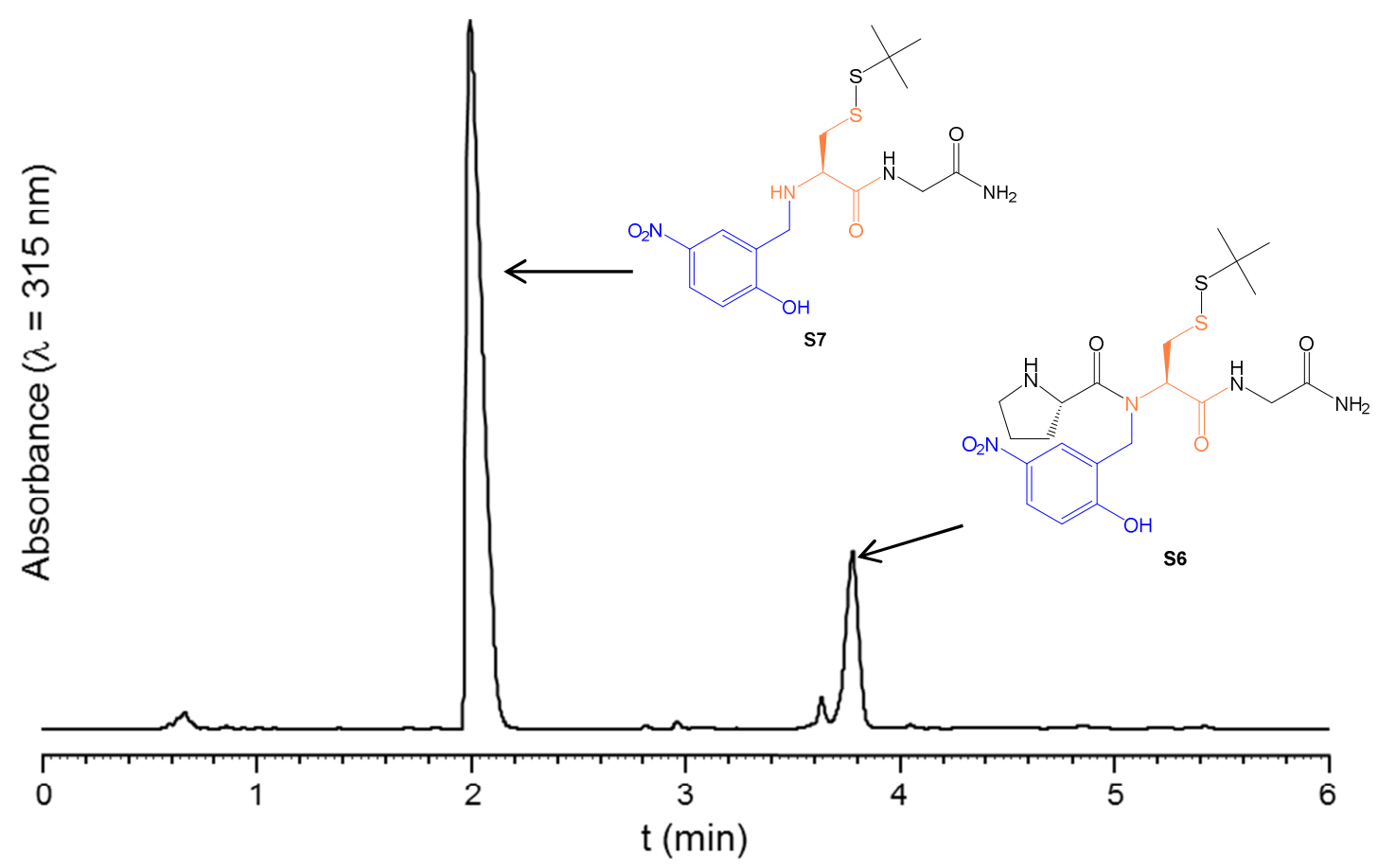

Supplementary figure S12: HPLC trace of crude $\mathbf{S} 6$ after a single standard coupling of Fmoc-Pro-OH (30 min) and without $\mathrm{Pr}_{2} \mathrm{NEt}$ treatment.

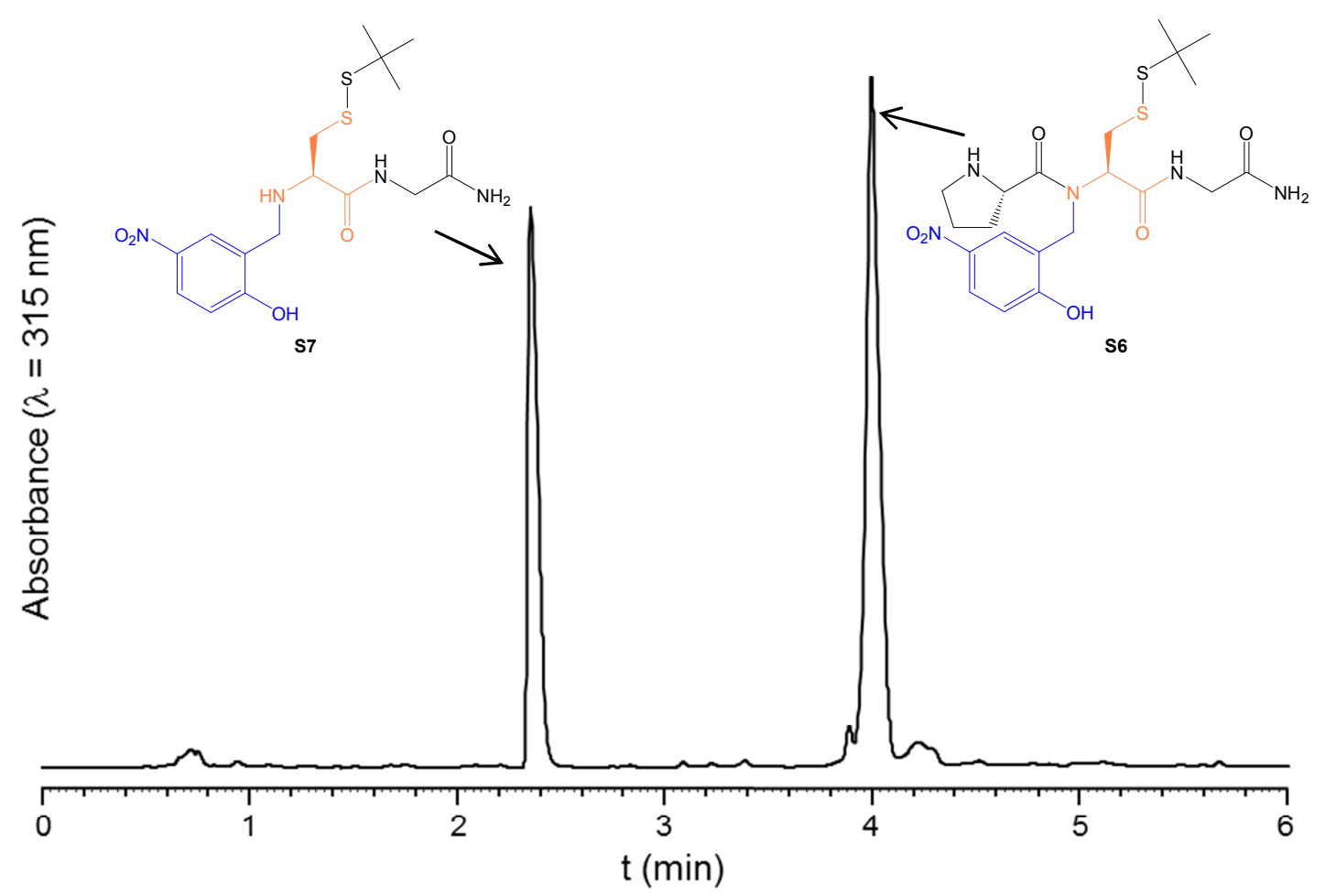

Supplementary figure S13: HPLC trace of crude $\mathbf{S 6}$ after a single standard coupling of Fmoc-Pro-OH (30 min) followed by $\mathrm{iPr}_{2} \mathrm{NEt}$ treatment (20 equiv., $24 \mathrm{~h}$ ). 


\section{Synthesis of [1-50] AhPDF1.1b-(Hnb)C(StBu)G- $-\mathrm{NH}_{2}(2)$}

Amino acid sequence of 2:

ZRLCEKPSGTWSGVCGNNGACRNQCIRLEKARHGSCNYVFPAHKCICYFP(Hnb)C(StBu)G-NH ${ }_{2}$ $\mathrm{Z}=$ pyroglutamic acid

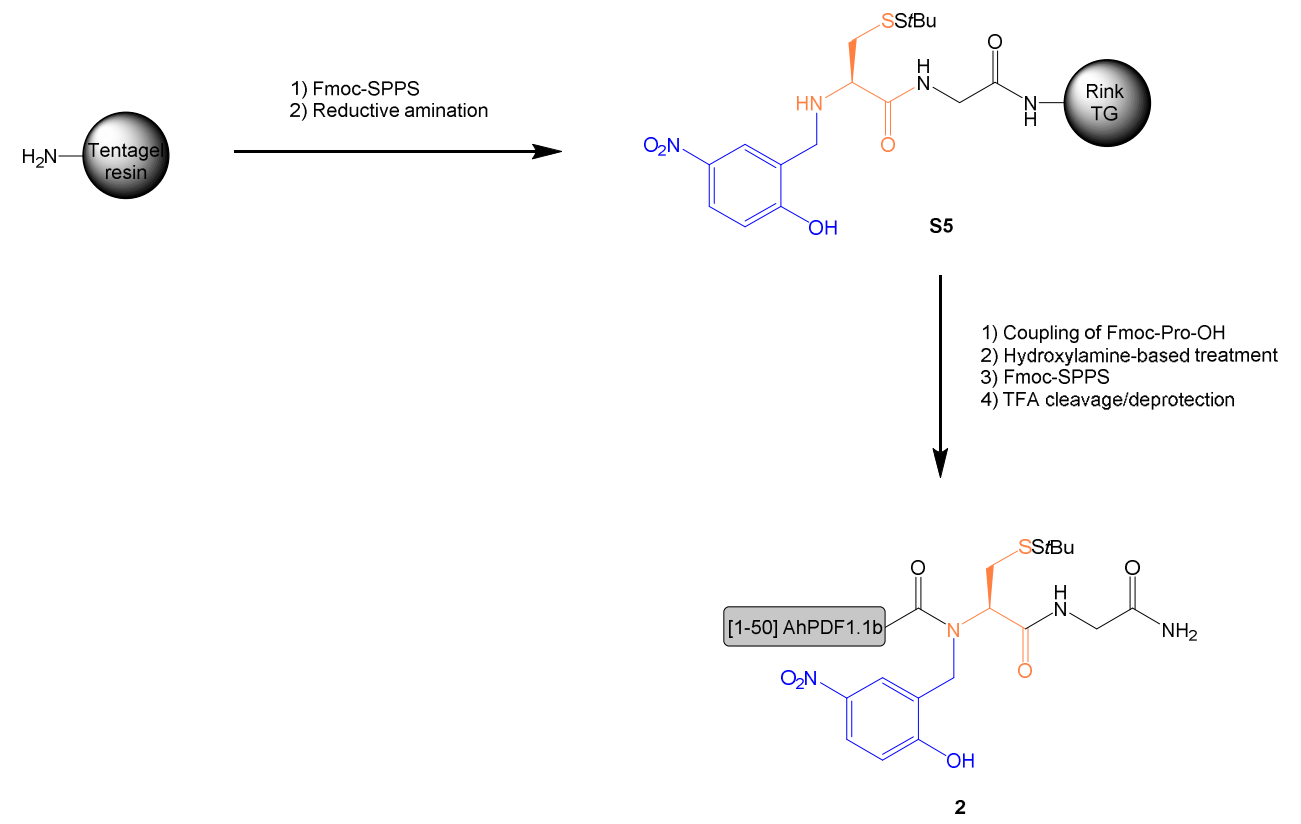

Supplementary scheme S8: Synthesis of 2.

Peptide 2 was obtained through automated SPPS using a Prelude synthesizer (protocol p S3) and using the automated reductive amination (protocol p S11) starting from aminomethyl Tentagel resin $(120 \mathrm{mg}, 0.21 \mathrm{mmol} / \mathrm{g}, 25 \mu \mathrm{mol})$. Fmoc-Pro-OH was coupled five times (see general procedure pS3) on the $\mathrm{N}$-Hnb-Cys device and a treatment of the peptide-resin using a solution of hydroxylamine hydrochloride $(0.3$ $\mathrm{M})$ and imidazole $(0.225 \mathrm{M})$ in a NMP $/ \mathrm{CH}_{2} \mathrm{Cl}_{2}$ mixture $(5: 1,20 \mathrm{~min}, 3 \mathrm{~mL}, \times 3)$ was performed. A capping step was performed (protocol p S3) then the $\mathrm{N}$-acylation yield $(50 \%)$ was quantified by UV titration of the fluorenylmethylpiperidine byproduct from the Fmoc removal at $\lambda=301 \mathrm{~nm}\left(\varepsilon^{301}=7800 \mathrm{~L} \cdot \mathrm{mol}^{-1} \cdot \mathrm{cm}^{-1}\right)$. The peptide sequence was elongated using standard SPPS (protocol p S3), a double coupling being performed for the last residue (pyroglutamic acid), before a final piperidine treatment. Elongation yield (55\%) was determined by UV titration of the fluorenylmethylpiperidine byproduct from the last Fmoc removal $\left(\operatorname{Arg}^{2}\right)$, as compared to the first one $\left(\mathrm{Pro}^{50}\right)$. For this purpose, after the coupling of $\mathrm{Arg}^{2}$ and prior to the piperidine treatment, peptide-resin was treated with a solution of hydroxylamine hydrochloride and imidazole as above described, in order to cleave any Fmoc$\mathrm{Arg}(\mathrm{Pbf})$ ester on the Hnb moiety. After cleavage and deprotection (protocol p S3), a part of crude 2 was purified by semi-preparative RP-HPLC at $70{ }^{\circ} \mathrm{C}$ (Nucleosil, gradient: $38-50 \%$ B/A over $20 \mathrm{~min}$ ). Pure peptide 2 was obtained in an overall yield of 
$15 \%$ (quantity of pure 2 determined by UV titration at $280 \mathrm{~nm}$, yield based on loading of Fmoc-P-(Hnb)C(StBu)-G-Rink-Tentagel resin and thus corresponding Fmoc SPPS elongation, TFA-mediated cleavage and deprotection, and purification).

\section{2}

ESI-HRMS (m/z): $[\mathrm{MH}]^{+}$calcd. for $\mathrm{C}_{255} \mathrm{H}_{390} \mathrm{~N}_{79} \mathrm{O}_{71} \mathrm{~S}_{9}: 5982.6822$, found: 5982.6806 . HPLC analysis: $t_{R}=33.7 \mathrm{~min}$ (Nucleosil, gradient: $20-54 \% \mathrm{~B} / \mathrm{A}$ over $45 \mathrm{~min}, 70^{\circ} \mathrm{C}$ ).

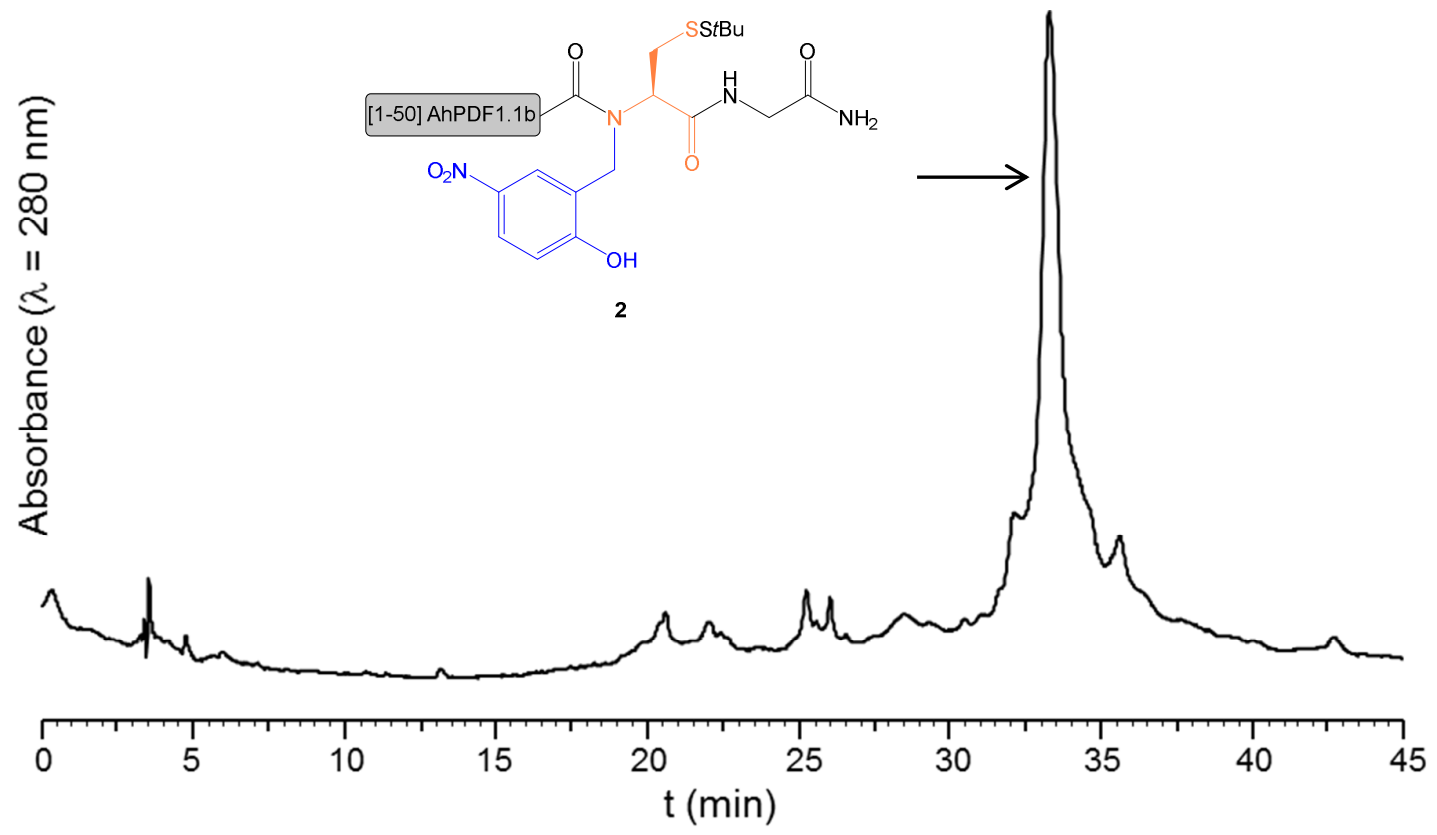

Supplementary figure S14: HPLC trace (Nucleosil, $70^{\circ} \mathrm{C}$ ) of crude 2.

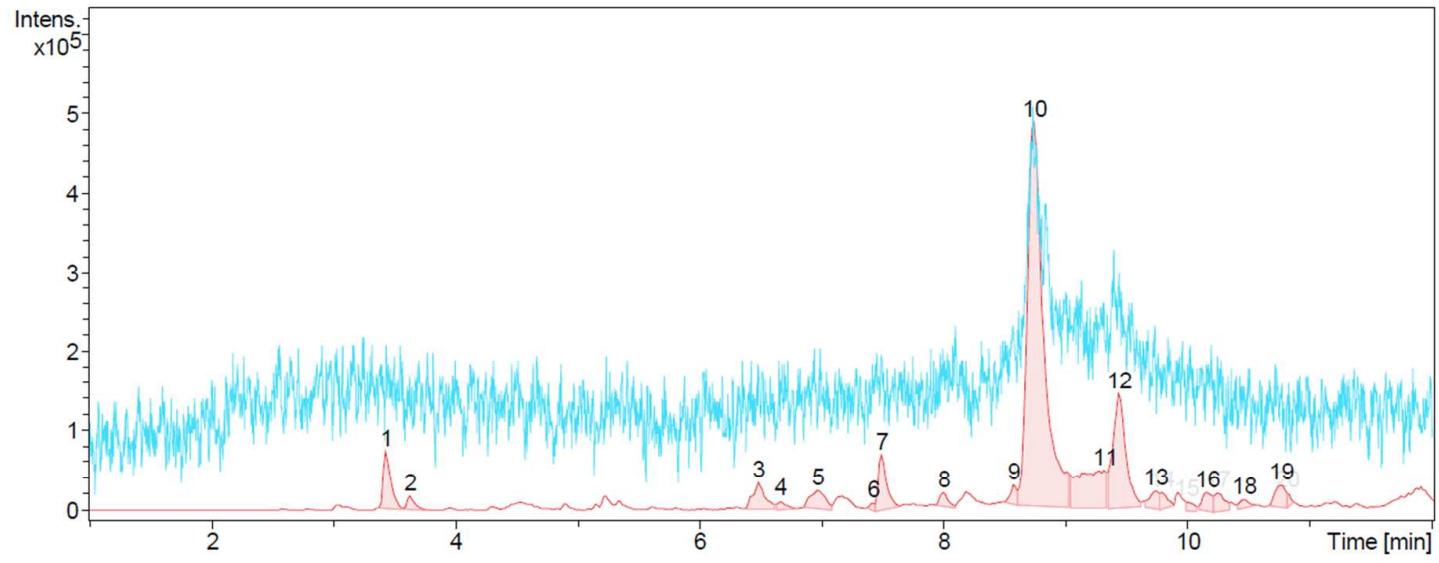

Supplementary figure S15: LC/MS analysis of crude 2. Blue trace: UV $(\lambda=214 \mathrm{~nm})$; red trace: base peak ion chromatogram. 
Note that the LC/MS analysis of crude 2 showed an unusual profile for the peak corresponding to compound 2: a first large peak (\#10) followed by a smaller one (\#12) separated by a plateau (\#11). Such a chromatographic profile is consistent with a conformational equilibrium, ${ }^{6}$ that we attributed to a slow trans/cis interconversion of the Pro-(Hnb)Cys $N, N$-disubstituted amide bond within the timeframe of the analysis. This hypothesis is relevant with the same peak-plateau-peak profile found in HPLC analysis at room temperature of purified 2 (figure S10), that clearly show a coalescence between the two peaks at higher temperature (figure S11).

\begin{tabular}{|c|c|c|c|}
\hline $\begin{array}{c}\text { Peak number } \\
\left(t_{R}(\min )\right)\end{array}$ & $\begin{array}{c}{[\mathrm{MH}]^{+}(\mathrm{m} / \mathrm{z})} \\
\text { calcd. }\end{array}$ & $\begin{array}{c}{[\mathrm{MH}]^{+}(\mathrm{m} / \mathrm{z})} \\
\text { found }\end{array}$ & Attributed to \\
\hline $7(7.49)$ & - & 5831.6519 & Not attributed \\
\hline $10(8.74)$ & 5982.6822 & 5982.6806 & $\mathbf{2}$ \\
\hline $12(9.43)$ & 5982.6822 & 5982.6809 & Conformer of 2 \\
\hline
\end{tabular}

Supplementary table S3: Attribution of the main peaks observed during LC/MS analysis of crude 2 .

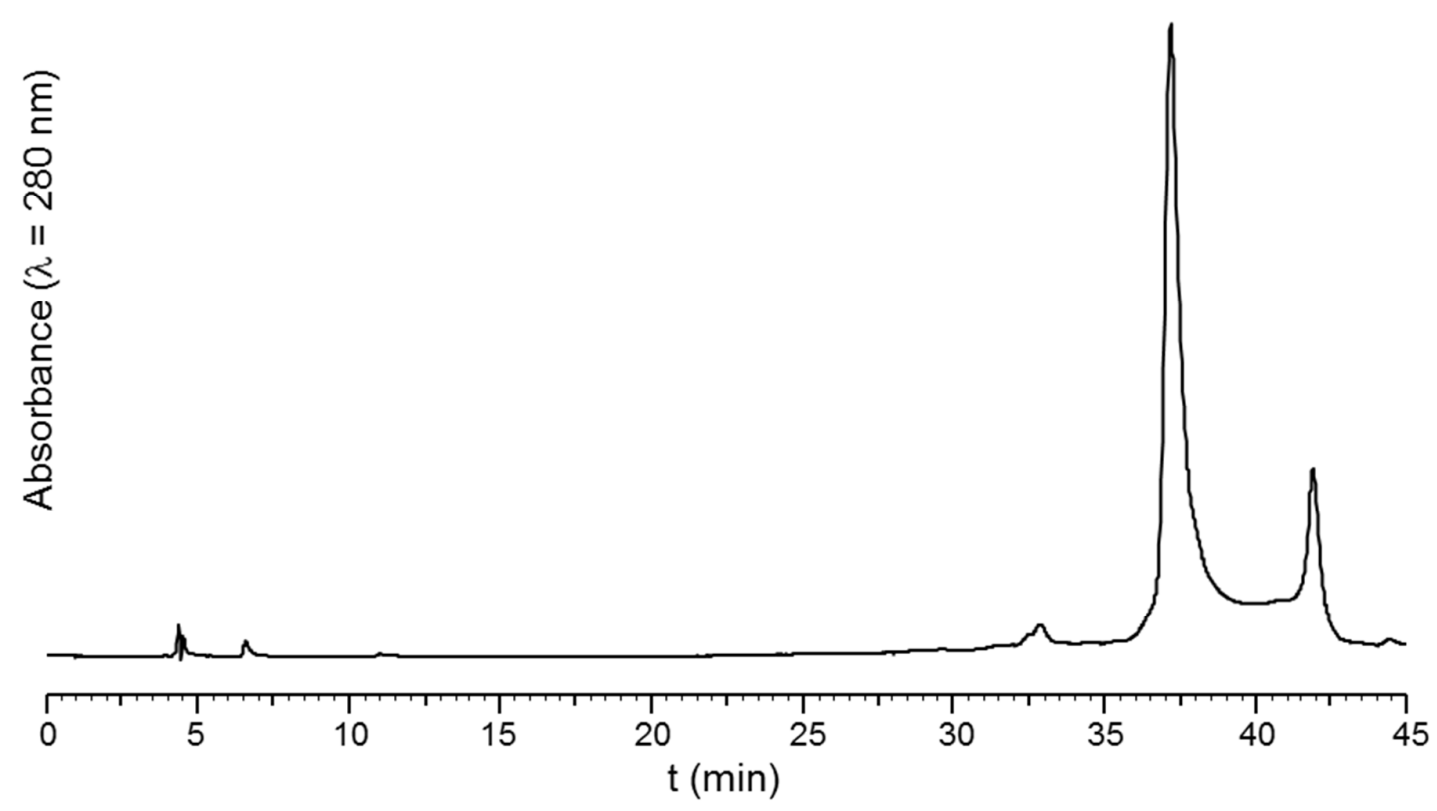

Supplementary figure S15: HPLC trace of purified $2,20^{\circ} \mathrm{C}$.

\footnotetext{
${ }^{6}$ See for example: a) Oxelbark, J.; Allenmark, S. J. Org. Chem. 1999, 64, 1483-1486. b) Shibukawa, Masami; Miyake, A.; Eda, S.; Saito, S. Anal. Chem. 2015, 87, 9280-9287.
} 


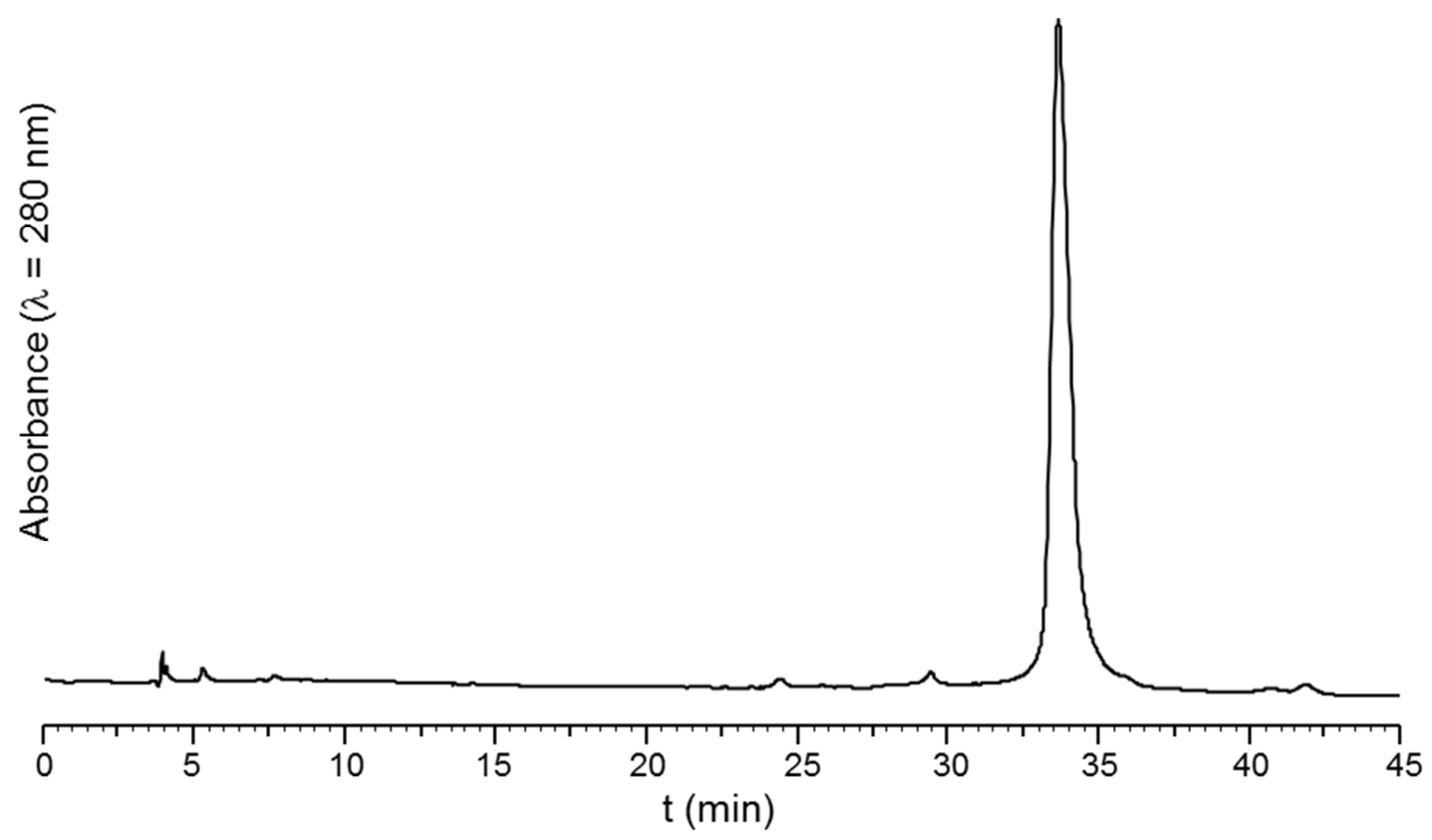

Supplementary figure S16: HPLC trace of purified $2,70{ }^{\circ} \mathrm{C}$. 


\section{Synthesis of [1-51] AhPDF1.1b (1) via NCL}

\section{6a- Optimization of the NCL conditions}

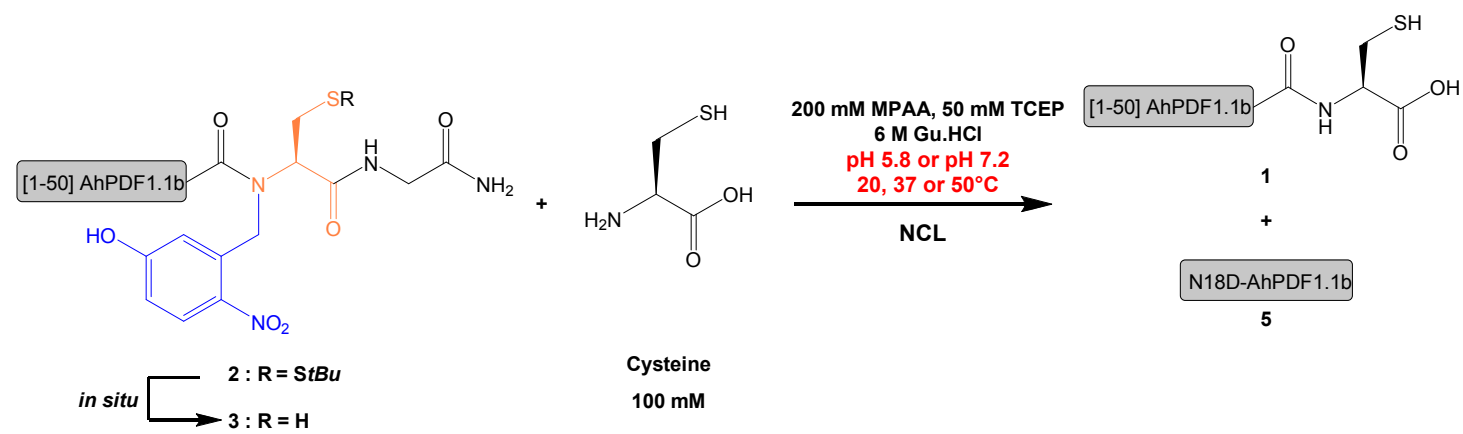

Supplementary scheme S9: NCL using HPLC-purified 2 to obtain 1.

\section{NCL conditions optimization (see table 1 of the article body):}

$80 \mu \mathrm{l}$ of a deoxygenated ${ }^{\mathrm{a}} 0.2 \mathrm{M}(\mathrm{pH}=$ either 5.8 or 7.2 , see table 1) sodium phosphate buffer containing $200 \mathrm{mM}$ 4-mercaptophenylacetic acid (MPAA), $50 \mathrm{mM}$ tris-carboxyethylphosphine (TCEP), $6 \mathrm{M}$ guanidine hydrochloride $(\mathrm{Gu} . \mathrm{HCl})$ and 100 $\mathrm{mM}$ cysteine was added to HPLC-purified peptide $2\left(0.08 \mu \mathrm{mol}^{\mathrm{b}}\right)$ (final concentration $1 \mathrm{mM}$ ), under argon. Ligations were carried out at either 20,37 or $50{ }^{\circ} \mathrm{C}$ and monitored by RP-HPLC. For this, $5 \mu \mathrm{L}$ aliquots of the reaction mixture were diluted with $100 \mu \mathrm{L}$ of $2 \%$ TFA in water and injected in HPLC. Yields were quantified by integrations of the HPLC peaks $(\lambda=280 \mathrm{~nm})$ corresponding to compounds $\mathbf{3}$ and $\mathbf{1 / 4}$, taking into account the absorbance of the $\mathrm{N}$-Hnb-Cys device $\left(\varepsilon^{280} \mathrm{Hnb}=3440\right.$ $\mathrm{L} \cdot \mathrm{mol}^{-1} \cdot \mathrm{cm}^{-1}, \varepsilon^{280} \mathbf{3}=11520 \mathrm{~L} \cdot \mathrm{mol}^{-1} \cdot \mathrm{cm}^{-1}, \varepsilon^{280} \mathbf{1}$ and $\mathbf{5}=8080 \mathrm{~L} \cdot \mathrm{mol}^{-1} \cdot \mathrm{cm}^{-1}$ in 8:2:0.01 $\mathrm{H}_{2} \mathrm{O} / \mathrm{MeCN} / \mathrm{TFA}$ ). The relative amount of $\mathbf{1}$ and $\mathbf{5}$-not well separated under the analytical HPLC conditions used for monitoring NCL- was determined by integration of the extracted ion chromatogram from the LC/MS analyses corresponding to both compounds, neglecting the eventual differences in terms of ionization of the two compounds.

Reaction at $\mathrm{pH}=5.8$ and $50^{\circ} \mathrm{C}$ for $48 \mathrm{~h}$ were found to be optimal conditions for this reaction (see Table 1 of the article).

${ }^{a}$ : Deoxygenation was performed through four consecutive vacuum/argon cycles.

${ }^{\mathrm{b}}$ : Quantified by UV titration at $280 \mathrm{~mm}$ of pure 2 .

1

ESI-HRMS (m/z): [MH] $]^{+}$calcd. for $\mathrm{C}_{242} \mathrm{H}_{373} \mathrm{~N}_{76} \mathrm{O}_{68} \mathrm{~S}_{8}: 5687.5831$, found: 5687.5864 . HPLC analysis: $t_{R}=26.9$ min (Nucleosil, gradient: $10-50 \%$ B/A over $40 \mathrm{~min}, 70{ }^{\circ} \mathrm{C}$ ). 


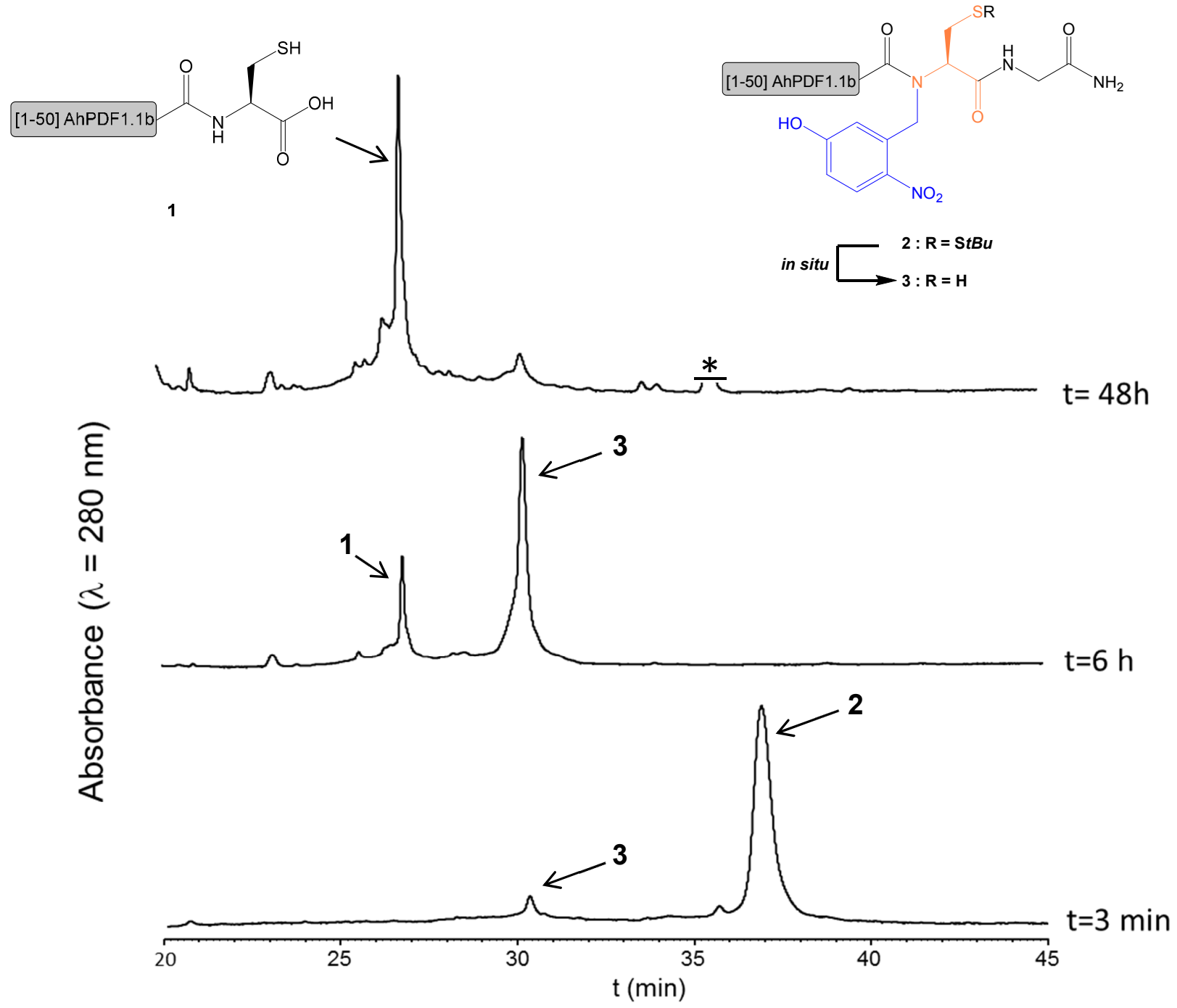

Supplementary figure S17: Analytical HPLC monitoring at $70^{\circ} \mathrm{C}$ of the $\mathrm{NCL}$ reaction at $\mathrm{pH} 5.8$ at $50^{\circ} \mathrm{C}$ with purified 2 to obtain peptide 1 . $^{*}$ : MPAA disulfide

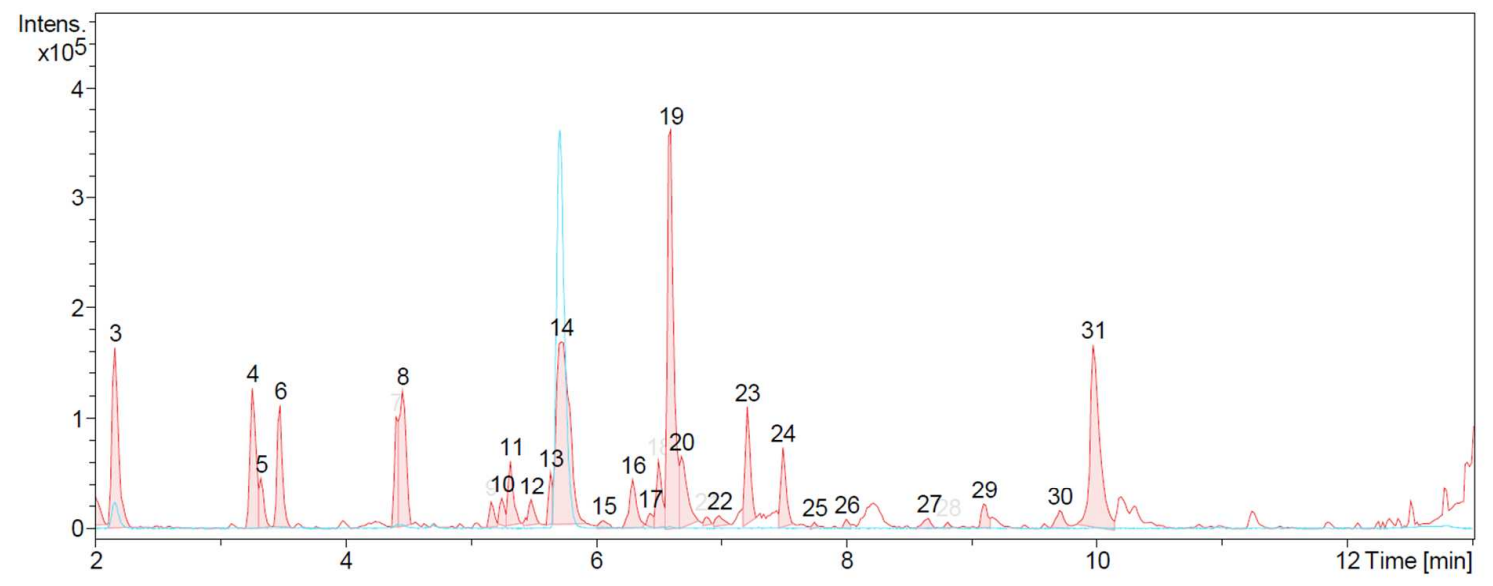

Supplementary figure S18: LC/MS analysis of NCL to obtain 1 after $48 \mathrm{~h}$ at $\mathrm{pH} 5.8$ at $50^{\circ} \mathrm{C}$. Blue trace: UV $(\lambda=214 \mathrm{~nm})$; red trace: base peak ion chromatogram. 


\begin{tabular}{|c|c|c|c|}
\hline $\begin{array}{c}\text { Peak number } \\
\left(t_{R}(\min )\right)\end{array}$ & $\begin{array}{c}{[\mathrm{MH}]^{+}(m / z)} \\
\text { calcd. }\end{array}$ & $\begin{array}{c}{[\mathrm{MH}]^{+}(m / z)} \\
\text { found }\end{array}$ & Attributed to \\
\hline $3(2.16)$ & - & 409.1870 & Not attributed \\
\hline $4(3.26)$ & - & 373.0867 & Not attributed \\
\hline $6(3.48)$ & - & 502.2439 & Not attributed \\
\hline $8(4.46)$ & - & 418.9847 & Not attributed \\
\hline $14(5.72)$ & $289.0357^{a}$ & $289.0344^{a}$ & MPAA $^{a}$ \\
\hline $16(6.29)$ & 3659.6889 & 3659.6897 & $\mathrm{H}-[21-51]$ AhPDF 1.1 $\mathrm{b}^{\mathrm{b}}$ \\
\hline $18(6.50)$ & 3158.4771 & 3158.4790 & $\mathrm{H}-[25-51]$ AhPDF1.1b \\
\hline $18(6.50)$ & 5584.5740 & 5584.5595 & [1-50] AhPDF1.1 $\mathrm{b}^{\mathrm{C}}$ \\
\hline $19(6.60)$ & 5687.5831 & 5687.5864 & 1 \\
\hline $20(6.68)$ & 5688.5909 & 5688.5874 & $5^{\mathrm{d}}$ \\
\hline $20(6.68)$ & 5670.5561 & 5670.5652 & $1-17 \mathrm{Da}^{\mathrm{e}}$ \\
\hline $23(7.20)$ & 848.3145 & 848.3128 & $\mathrm{H}-[45-51]$ AhPDF 1.1 $\mathrm{b}^{\mathrm{b}}$ \\
\hline $24(7.49)$ & 1907.8105 & 1907.8092 & $\mathrm{H}-[35-51]$ AhPDF1.1 $\mathrm{b}^{\mathrm{b}}$ \\
\hline $31(9.97)$ & $352.0677^{\dagger}$ & $352.0661^{\dagger}$ & MPAA disufide \\
\hline
\end{tabular}

\section{Supplementary table S4: Attribution of the main peaks observed during LC/MS analysis of $\mathrm{NCL}$ to obtain 1 after $48 \mathrm{~h}$ at $\mathrm{pH} 5.8$ at $50^{\circ} \mathrm{C}$.}

a: Attribution based on the characteristic UV spectrum of this compound, and on the corresponding HPLC chromatogram showing a peak at the expected retention time for MPAA. Note that under our MS conditions, no peaks corresponding to the expected $\mathrm{m} / \mathrm{z}$ for protonated MPAA neither cation adducts were observed. A possible explanation for the observed $\mathrm{m} / \mathrm{z}$ could be oxidation into disulfide then decarboxylation to yield a benzyl cation $\left(\mathrm{C}_{15} \mathrm{H}_{13} \mathrm{O}_{2} \mathrm{~S}_{2}\right.$, calcd. $\left.\mathrm{m} / \mathrm{z} 289.0357\right)$. Note that minor peaks corresponding to $\mathrm{M}+\mathrm{Na}^{+}$and $\mathrm{M}+\mathrm{NH}_{4}{ }^{+}$relative to the disulfide were also observed.

${ }^{\mathrm{b}}$ : Traces of non-acetylated truncated peptides containing a $\mathrm{N}$-terminal Cys residue were observed in the LC/MS analysis of the mixture. These co-products were attributed to in situ $N \rightarrow S$ shift at Xaa-Cys sites followed by trans-thioesterification, as reported by MacMillan. ${ }^{7}$ Note that the ion chromatogram signal is not representative of the actual proportion of these peptides, as compared with the HPLC-UV analysis. Smaller peptides are expected to lead to a higher BPC signal due to greater ionization.

c: [1-50] AhPDF1.1b corresponds to a co-product arising from hydrolysis of peptide crypto-thioester 3 . [1-50] AhPDF1.1b proportion was evaluated to $6 \%$ relative to 1 by integration of the corresponding extracted ion chromatograms, neglecting the eventual differences in terms of ionization of the two compounds.

d: Compound 5 proportion was evaluated to $13 \%$ relative to 1 by integration of the extracted ion chromatogram corresponding to both $\mathbf{1}$ and $\mathbf{5}$, neglecting the eventual differences in terms of ionization of the two compounds.

${ }^{e}$ : The proportion of this compound, attributed to aspartimide formation at the $\mathrm{N}^{18} \mathrm{G}$ site, was evaluated to $4.6 \%$ relative to 1 by integration of the corresponding extracted ion chromatograms, neglecting the eventual differences in terms of ionization.

f: The calculated $\mathrm{m} / \mathrm{z}$ value corresponds to a $\left[\mathrm{M}+\mathrm{NH}_{4}\right]^{+}$form $\left(\mathrm{C}_{16} \mathrm{H}_{18} \mathrm{NO}_{4} \mathrm{~S}_{2}\right) . \mathrm{A}[\mathrm{M}+\mathrm{Na}]^{+}$species is also observed. A minor peak consistent with decarboxylation to yield a benzyl cation (see note a) is also observed.

\footnotetext{
${ }^{7}$ Cowper, B.; Shariff, L.; Chen, W.; Gibson,S. M.; Diab W.-L.; Macmillan, D. Org. Biomol. Chem., 2015, 13, $7469-7476$.
} 


\section{6b- Application to crude crypto-thioester 2}

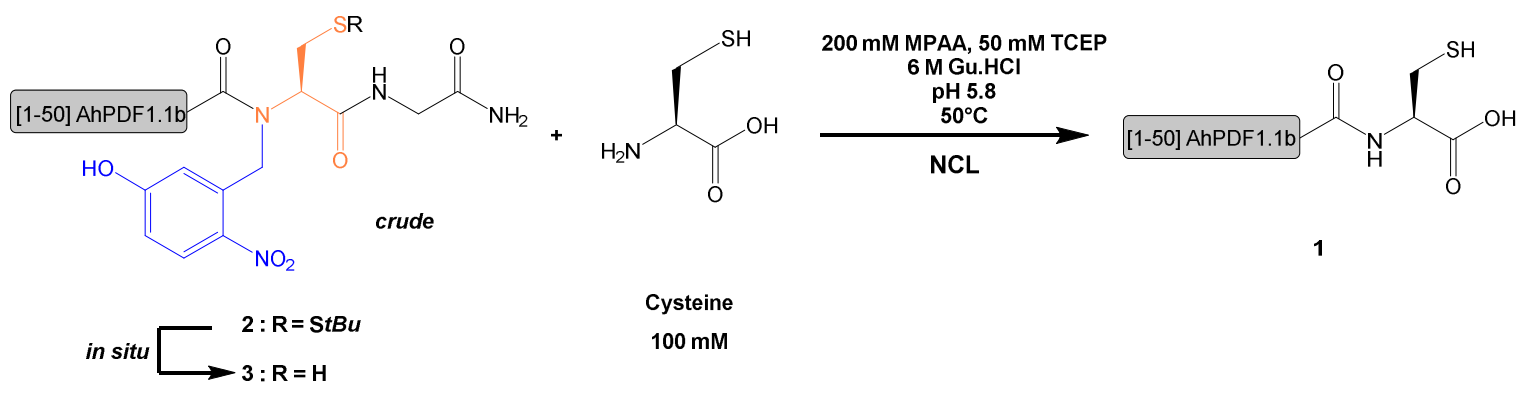

Supplementary scheme S10: NCL using crude 2 to obtain 1.

\section{NCL under optimized conditions:}

$800 \mu \mathrm{L}$ of a deoxygenated ${ }^{\mathrm{a}} 0.2 \mathrm{M} \mathrm{pH} 5.8$ sodium phosphate buffer containing 200 $\mathrm{mM}$ MPAA, $50 \mathrm{mM}$ TCEP, $6 \mathrm{M}$ guanidine hydrochloride and $100 \mathrm{mM}$ cysteine was added to crude dry peptide 2 (8 $\mathrm{mg}$, corresponding to $1.3 \mu \mathrm{mol}$ of the crude cryptothioester mixtures, ${ }^{b}$ and $0.72 \mu \mathrm{mol}$ of $\mathbf{2}^{\mathrm{c}}$ ) under argon. Ligation was carried out at 50 ${ }^{\circ} \mathrm{C}$ and monitored by RP-HPLC. After 48h, TCEP (100 mM final concentration) was added to the reaction mixture and $\mathrm{pH}$ was adjusted to 6.0 using a $10 \mathrm{M} \mathrm{NaOH}$ solution to reduce disulfides possibly formed due to oxygen contamination. After $1 \mathrm{~h}$, $\mathrm{pH}$ was adjusted to 1 with $1.5 \%$ TFA in water and ligation product 1 was purified by semi-preparative RP-HPLC (Nucleosil, gradient: 30-36\% B/A over 12 min). 1 was isolated with an overall yield of $13.4 \%$ (based on the loading of Fmoc-Pro$(\mathrm{Hnb}) \mathrm{C}(\mathrm{StBu})-\mathrm{G}-\mathrm{Rink}-T e n t a g e l$ resin, and thus corresponding Fmoc SPPS elongation, TFA-mediated cleavage and deprotection, NCL and purification).

a: deoxygenation was performed through four consecutive vacuum/argon cycles.

b: Quantity of crude peptide crypto-thioester mixture evaluated from the Fmoc-Pro-(Hnb)C(StBu)-GRink-Tentagel resin loading, as determined by UV titration of the fluorenylmethylpiperidine byproduct from the Fmoc removal $\left(\varepsilon^{301}=7800 \mathrm{~L} \cdot \mathrm{mol}^{-1} \cdot \mathrm{cm}^{-1}\right)$.

${ }^{c}$ : As evaluated from the SPPS elongation yield (55\%).

ESI-HRMS $(\mathrm{m} / \mathrm{z}):[\mathrm{MH}]^{+}$calcd. for $\mathrm{C}_{242} \mathrm{H}_{373} \mathrm{~N}_{76} \mathrm{O}_{68} \mathrm{~S}_{8}: 5687.5831$ found: 5687.5751. HPLC analysis: $t_{R}=3.9$ min (Chromolith, gradient: $20-50 \%$ B/A over 9 min). 


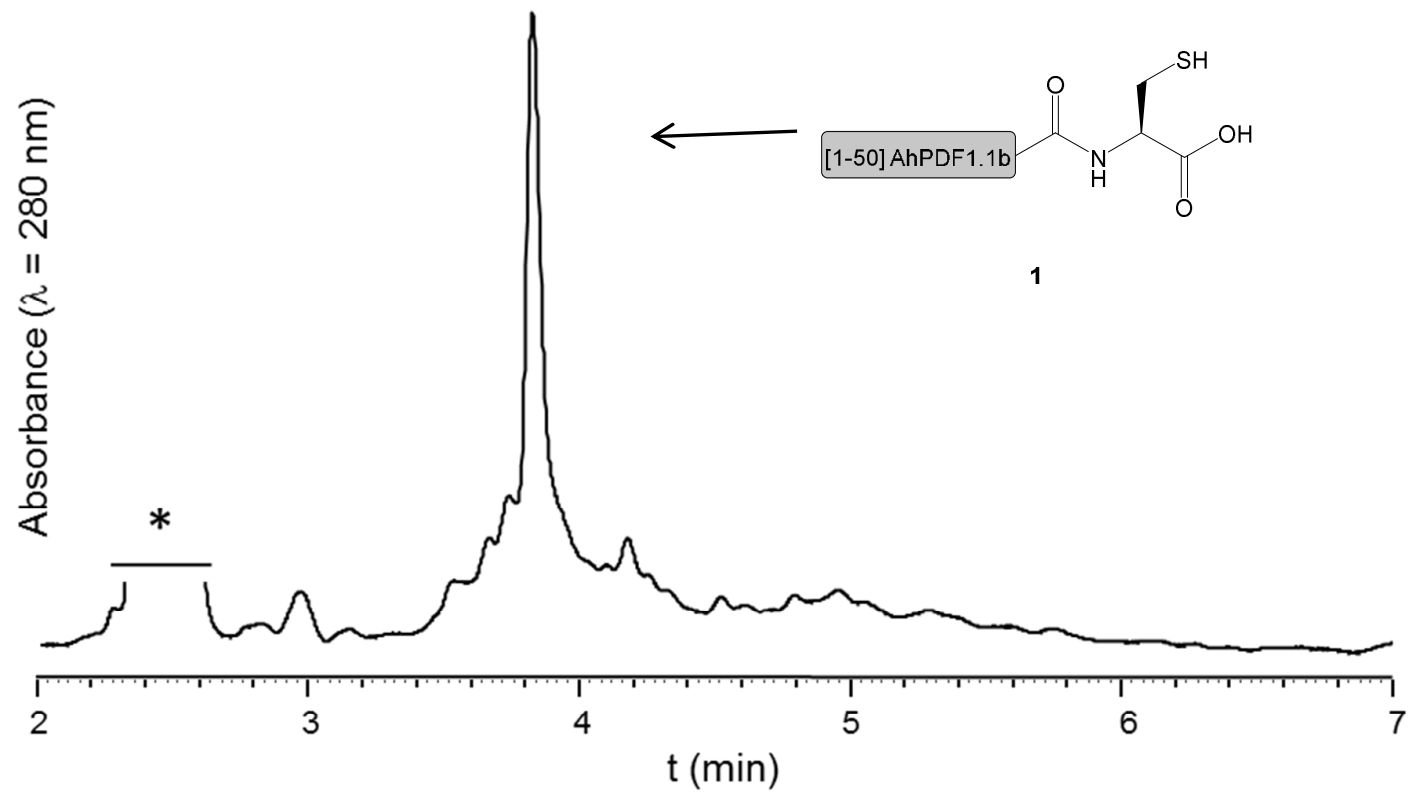

Supplementary figure S19: HPLC trace of crude reduced 1 after $42 \mathrm{~h}$ of NCL. (*: MPAA).

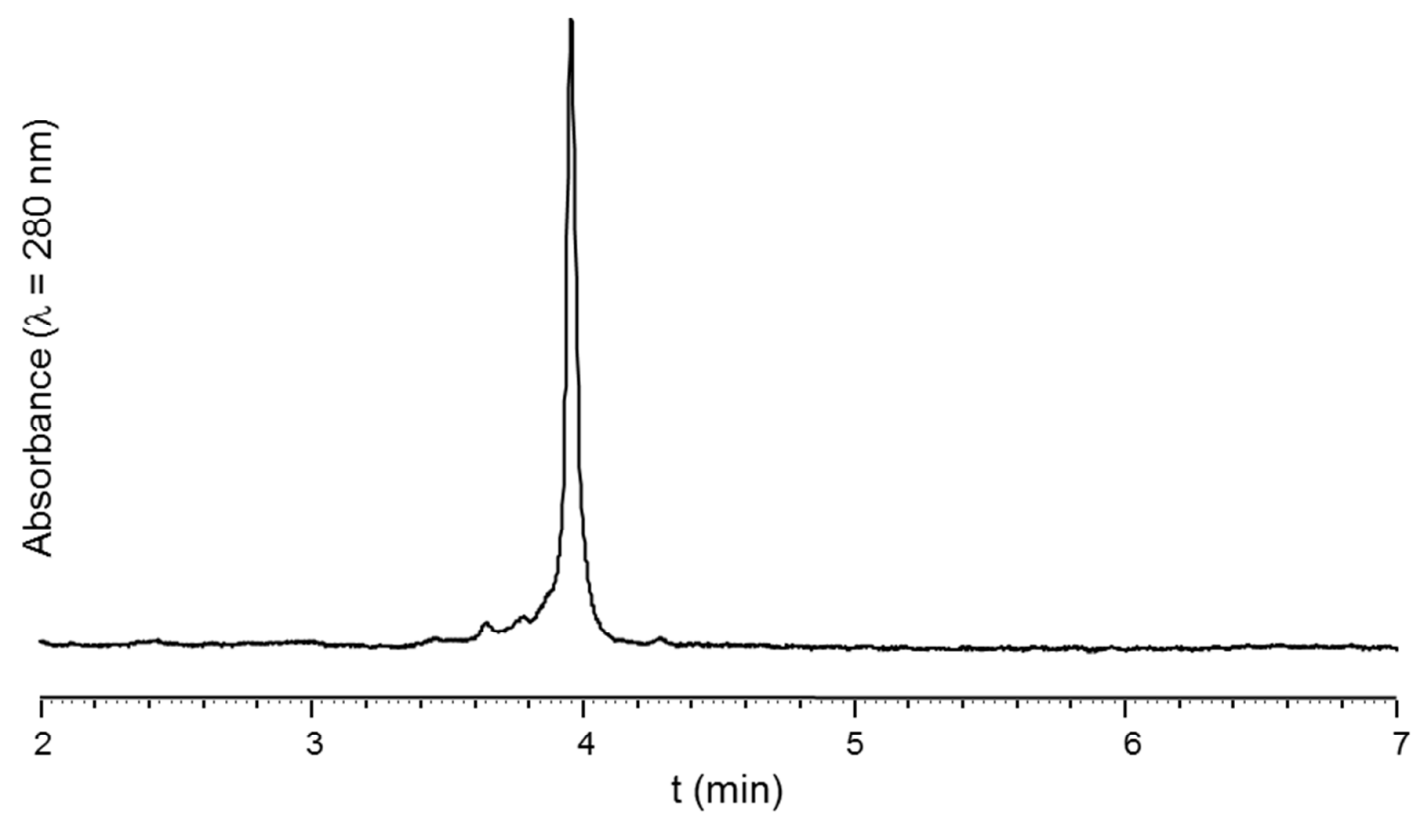

Supplementary figure S20: HPLC trace of purified 1. 


\section{Application to the synthesis of [1-51] AhPDF1.5 (7)}

\section{7a- Synthesis of [1-50] AhPDF1.5-(Hnb)C(StBu)G- $\mathrm{NH}_{2}(6)$}

Amino acid sequence of $\mathbf{6}$ :

ZLCKRESETWSGRCVNDYQCRDHCINNDRGNDGYCAGGYPWYRGCFCFFS(Hnb)C(StBu)G-NH $\mathrm{N}_{2}$ $\mathrm{Z}=$ pyroglutamic acid

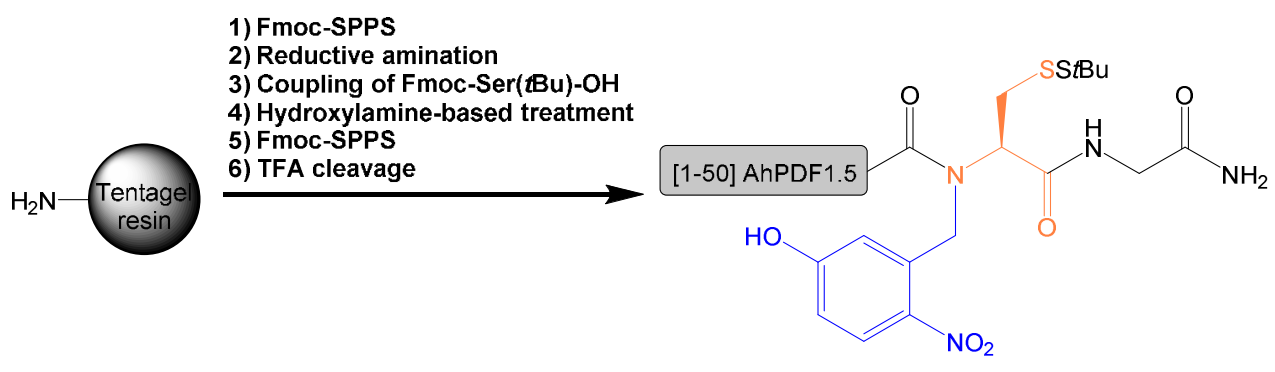

\section{Supplementary scheme S11: Synthesis of 6.}

Peptide 6 was obtained through automated SPPS using a Prelude synthesizer (protocol p S3) and using the automated reductive amination (protocol p S11) starting from aminomethyl Tentagel resin (120 mg, $0.21 \mathrm{mmol} / \mathrm{g}, 25 \mu \mathrm{mol})$. Fmoc-Ser(tBu)$\mathrm{OH}$ was coupled five times (see general procedure pS3) on the $\mathrm{N}-\mathrm{Hnb}$-Cys device and a treatment of the peptide-resin using a solution of hydroxylamine hydrochloride $(0.3 \mathrm{M})$ and imidazole $(0.225 \mathrm{M})$ in a NMP / $\mathrm{CH}_{2} \mathrm{Cl}_{2}$ mixture $(5: 1,20 \mathrm{~min}, 3 \mathrm{~mL}, \times 3)$ was performed. A capping step was performed (protocol p S3) then the $\mathrm{N}$-acylation yield $(85 \%)$ was quantified by UV titration of the fluorenylmethylpiperidine byproduct from the Fmoc removal $\left(\varepsilon^{301}=7800 \mathrm{~L} \cdot \mathrm{mol}^{-1} \cdot \mathrm{cm}^{-1}\right)$. The peptide sequence was elongated using standard SPPS (protocol p S3), a double coupling being performed for the last residue (pyroglutamic acid), before a final piperidine treatment. Elongation yield $(56 \%)$ was determined by UV titration of the fluorenylmethylpiperidine byproduct from the last Fmoc removal $\left(\mathrm{Leu}^{2}\right)$, as compared to the first one $\left(\mathrm{Ser}^{50}\right)$. For this purpose, after the coupling of $\mathrm{Leu}^{2}$ and prior to the piperidine treatment, peptide-resin was treated with a solution of hydroxylamine hydrochloride and imidazole as above described, in order to cleave any Fmoc-Leu ester on the Hnb moiety. After TFAmediated cleavage of the peptide from the resin and deprotection (protocol p S3), 6 was directly used in a NCL reaction without further purification.

\section{6}

ESI-HRMS (m/z): [MH] $]^{+}$calcd. for $\mathrm{C}_{266} \mathrm{H}_{376} \mathrm{~N}_{79} \mathrm{O}_{81} \mathrm{~S}_{9}$ : 6260.5218 , found: 6260.5363 . HPLC analysis: $t_{R}=7.03$ min (Chromolith, gradient: $20-50 \%$ B/A over 9 min). 


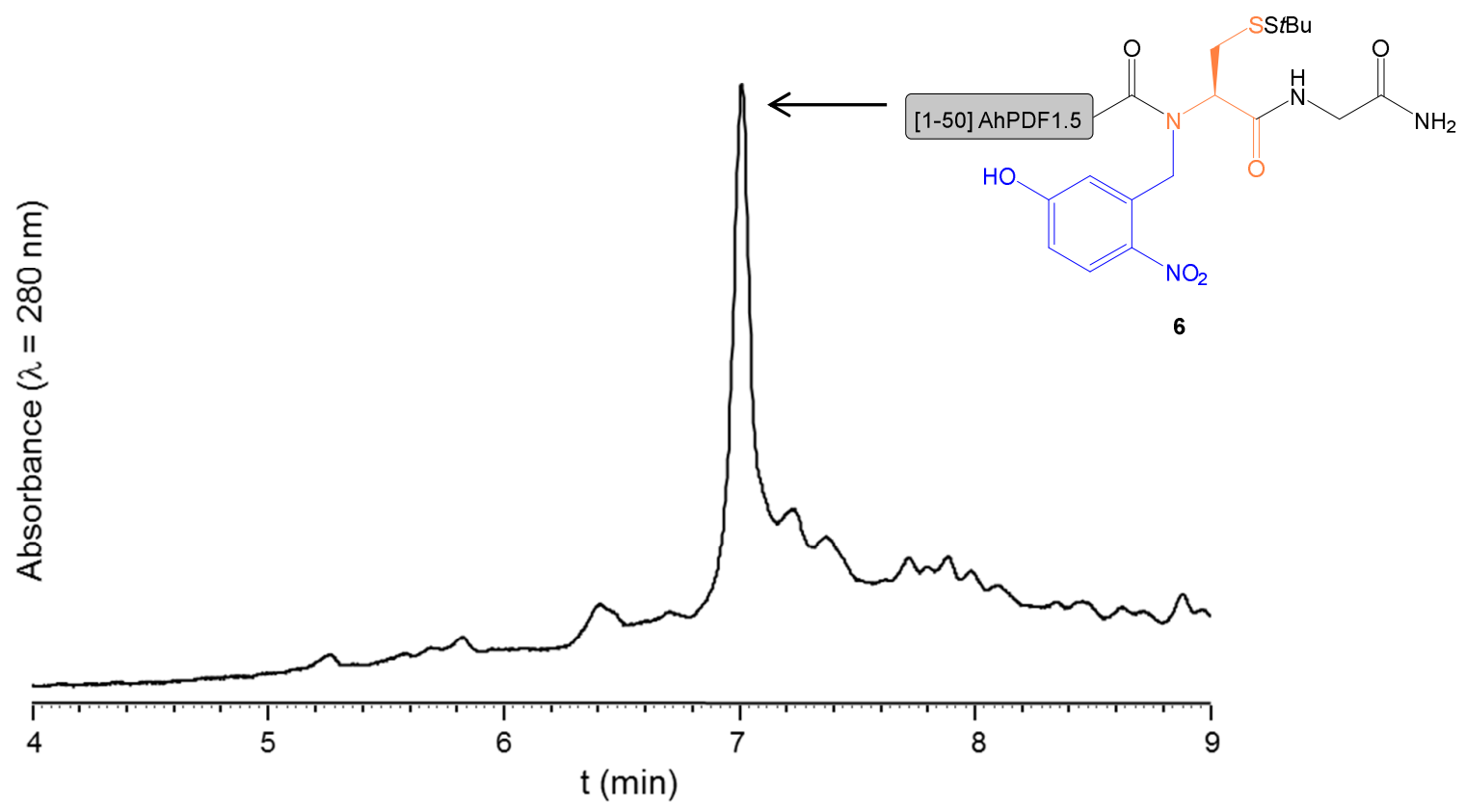

Supplementary figure S21: HPLC trace of crude 6.

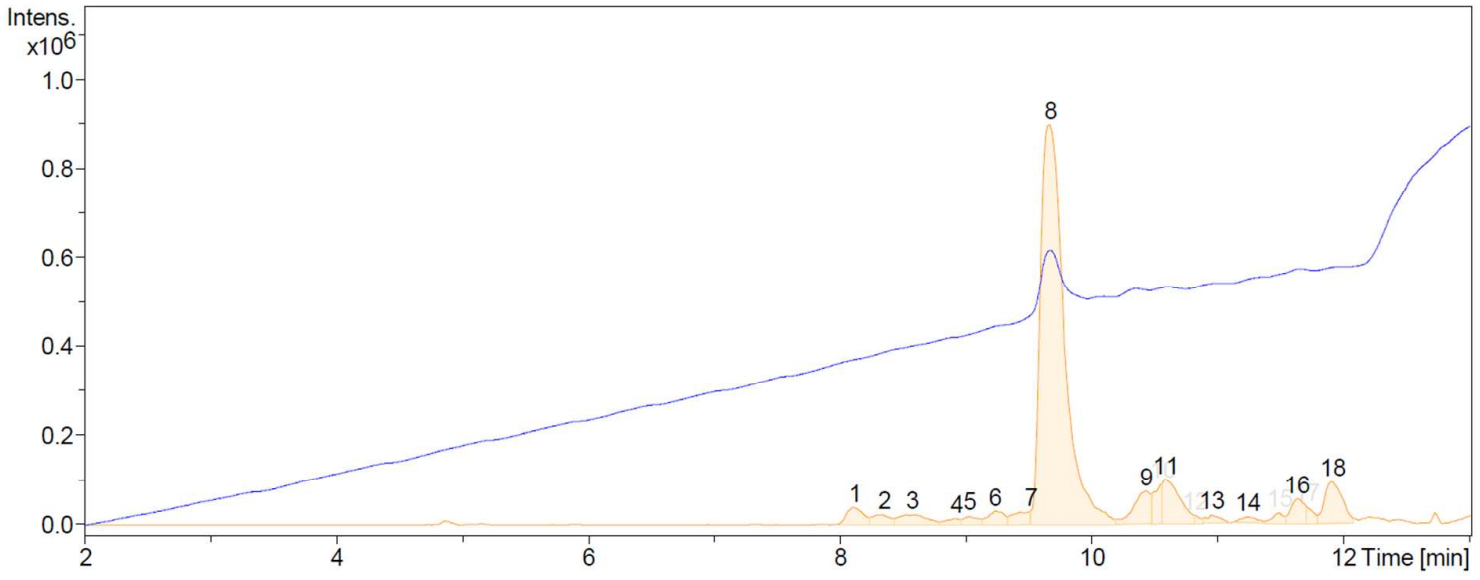

Supplementary figure S22: LC/MS analysis of crude 5. Blue trace: UV $(\lambda=214 \mathrm{~nm})$; red trace: base peak ion chromatogram.

\begin{tabular}{|c|c|c|c|}
\hline $\begin{array}{c}\text { Peak number } \\
\left(\mathrm{t}_{R}(\mathrm{~min})\right)\end{array}$ & $\begin{array}{c}{[\mathrm{MH}]^{+}(\mathrm{m} / \mathrm{z})} \\
\text { calcd. }\end{array}$ & $\begin{array}{c}{[\mathrm{MH}]^{+}(\mathrm{m} / \mathrm{z})} \\
\text { found }\end{array}$ & Attributed to \\
\hline $8(9.67)$ & 6260.5218 & 6260.5363 & $\mathbf{6}$ \\
\hline $11(10.58)$ & 6512.6038 & 6512.6134 & $\mathbf{6}+252 \mathrm{Da}(\mathrm{Pbf})$ \\
\hline $18(11.91)$ & 1852.7109 & 1852.7102 & $\begin{array}{c}\text { Ac-[39-50] AhPDF1.5b- } \\
(\mathrm{Hnb}) \mathrm{C}(\mathrm{StBu})-\mathrm{G}-\mathrm{NH}_{2}\end{array}$ \\
\hline
\end{tabular}

Supplementary table S5: Attribution of the main peaks observed during LC/MS analysis of crude 6 . 


\section{7b-Synthesis of 7 via NCL}

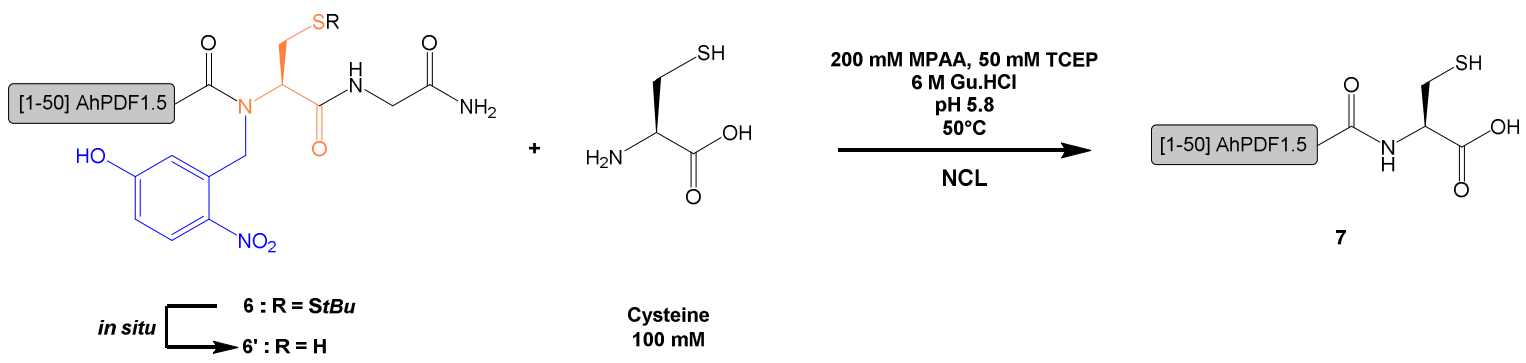

Supplementary scheme S12: NCL using crude 6 to obtain [1-51] AhPDF1.5 7.

$800 \mu \mathrm{L}$ of a deoxygenated ${ }^{\mathrm{a}} 0.2 \mathrm{M} \mathrm{pH} 5.8$ sodium phosphate buffer containing 200 $\mathrm{mM}$ MPAA, $50 \mathrm{mM}$ TCEP, $6 \mathrm{M}$ guanidine hydrochloride and $100 \mathrm{mM}$ cysteine was added to crude dry peptide 6 ( $8 \mathrm{mg}$, corresponding to $1.0 \mu \mathrm{mol}$ of the crude cryptothioester mixtures, ${ }^{b}$ and $0.56 \mu \mathrm{mol}$ of $6^{c}$ ) under argon. Ligation was carried out at 50 ${ }^{\circ} \mathrm{C}$ and monitored by RP-HPLC. For this, $5 \mu \mathrm{L}$ aliquots of the reaction mixture were diluted with $100 \mu \mathrm{L}$ of $2 \%$ TFA in water and injected in HPLC. After $5 \mathrm{~h}, \mathrm{pH}$ was adjusted to 1 with $1.5 \%$ TFA in water and ligation product 7 was purified by semipreparative RP-HPLC (Nucleosil, gradient: 35-45\% B/A over $20 \mathrm{~min}$ ). 7 was isolated with an overall yield of $15.8 \%$ (based on the loading of Fmoc-Ser $(t \mathrm{Bu})-(\mathrm{Hnb}) \mathrm{C}(\mathrm{StBu})-$ G-Rink-Tentagel resin, and thus corresponding Fmoc SPPS elongation, TFAmediated cleavage and deprotection, NCL and purification).

${ }^{a}$ : Deoxygenation was performed through four consecutive vacuum/argon cycles.

b: Quantity of crude peptide crypto-thioester mixture evaluated from the Fmoc-Ser-(Hnb)C(StBu)-GRink-Tentagel resin loading, as determined by UV titration of the fluorenylmethylpiperidine byproduct from the Fmoc removal $\left(\varepsilon^{301}=7800 \mathrm{~L} \cdot \mathrm{mol}^{-1} \cdot \mathrm{cm}^{-1}\right)$.

c: As evaluated from the SPPS elongation yield (56\%).

ESI-HRMS (m/z): $[\mathrm{MH}]^{+}$calcd. for $\mathrm{C}_{253} \mathrm{H}_{359} \mathrm{~N}_{76} \mathrm{O}_{78} \mathrm{~S}_{8}: 5965.4227$, found: 5965.4221 . HPLC analysis: $t_{R}=5.65$ min (Chromolith, gradient: $20-50 \%$ B/A over $9 \mathrm{~min}$ ). 


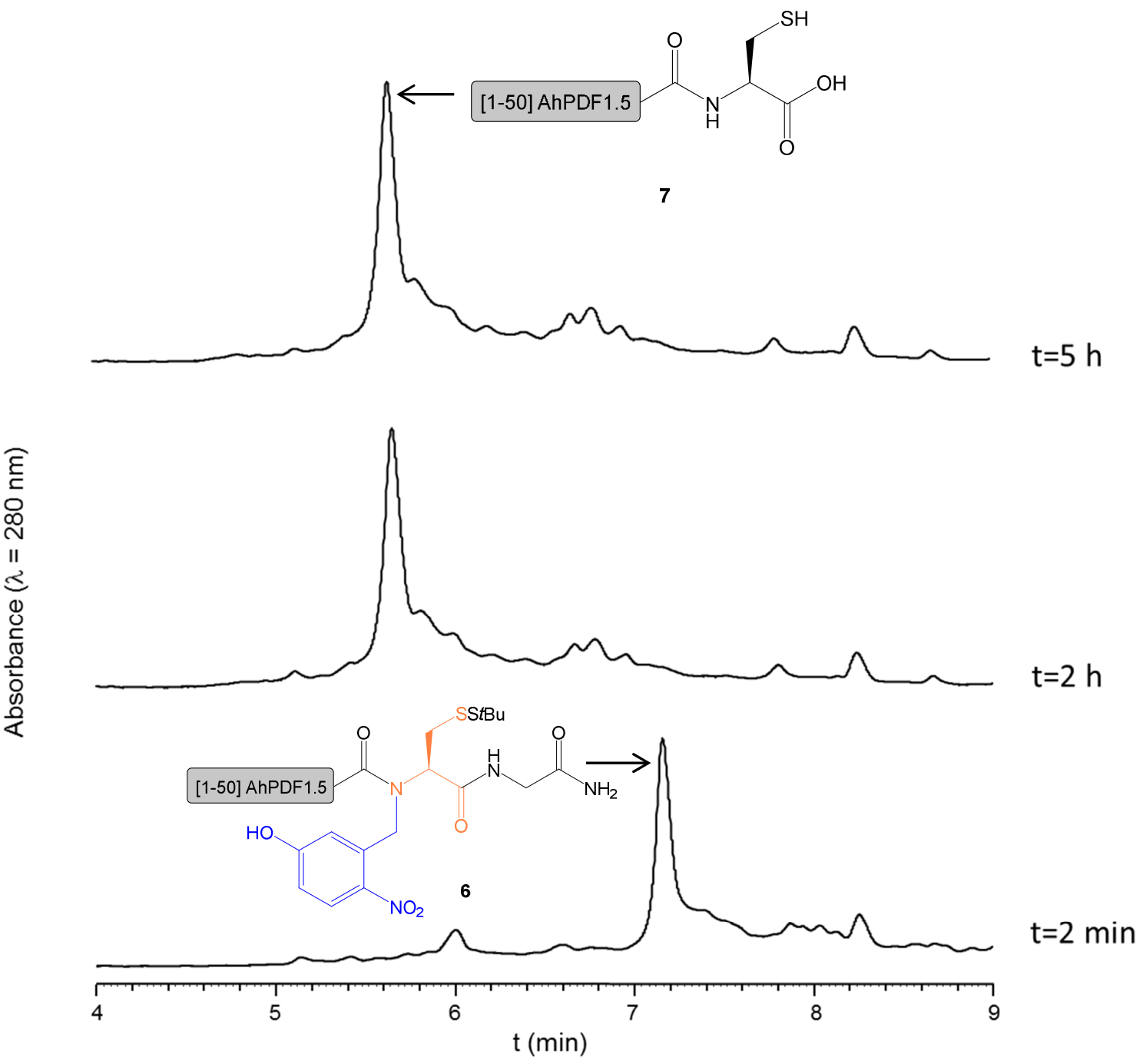

Supplementary figure S23: Analytical HPLC monitoring of the NCL reaction with crude 6 to obtain 7 showing completion of the reaction in $<2 \mathrm{~h}$.

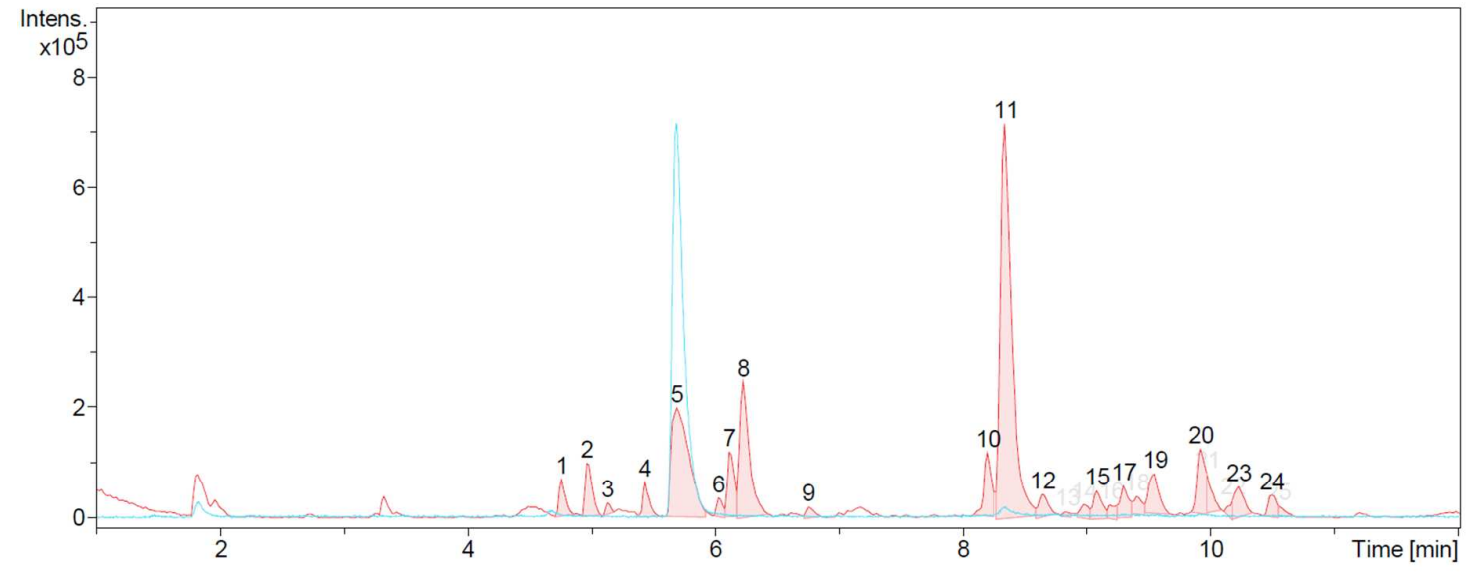

Supplementary figure S24: LC/MS analysis of NCL to obtain 7 after $6 \mathrm{~h}$. Blue trace: UV $(\lambda=214 \mathrm{~nm})$; red trace: base peak ion chromatogram. 


\begin{tabular}{|c|c|c|c|}
\hline $\begin{array}{c}\text { Peak number } \\
\left(\mathrm{t}_{\mathrm{R}}(\mathrm{min})\right)\end{array}$ & $\begin{array}{c}{[\mathrm{MH}]^{+}(\mathrm{m} / \mathrm{z})} \\
\text { calcd. }\end{array}$ & $\begin{array}{c}{[\mathrm{MH}]^{+}(\mathrm{m} / \mathrm{z})} \\
\text { found }\end{array}$ & Attributed to \\
\hline $5(5.69)$ & $289.0357^{\mathrm{a}}$ & $289.0442^{\mathrm{a}}$ & MPAA $^{\mathrm{a}}$ \\
\hline $8(6.23)$ & - & 469.1979 & Not attributed $^{\mathrm{a}}$ \\
\hline $10(8.20)$ & 856.2832 & 856.2811 & $\mathrm{H}-[45-51]$ AhPDF1.5 \\
\hline $10(8.20)$ & 5862.4130 & 5862.4092 & $\mathrm{H}-[1-50]$ AhPDF1.5 \\
\hline $11(8.33)$ & 5965.4227 & 5965.4221 & 7 \\
\hline $20(9.92)$ & $352.0677^{\mathrm{d}}$ & $352.0656^{\mathrm{d}}$ & MPAA disulfide $^{\mathrm{d}}$ \\
\hline
\end{tabular}

Supplementary table S6: Attribution of the main peaks observed during LC/MS analysis of NCL to obtain 7 after $6 \mathrm{~h}$.

a: Attribution based on the characteristic UV spectrum of this compound, and on the corresponding HPLC chromatogram showing a peak at the expected retention time for MPAA. Note that under our MS conditions, no peaks corresponding to the expected $\mathrm{m} / \mathrm{z}$ for protonated MPAA neither cation adducts were observed. A possible explanation for the observed $\mathrm{m} / \mathrm{z}$ could be oxidation into disulfide then decarboxylation to yield a benzyl cation $\left(\mathrm{C}_{15} \mathrm{H}_{13} \mathrm{O}_{2} \mathrm{~S}_{2}\right.$, calcd. $\left.\mathrm{m} / \mathrm{z} 289.0357\right)$. Note that minor peaks corresponding to $\mathrm{M}+\mathrm{Na}^{+}$and $\mathrm{M}+\mathrm{NH}_{4}{ }^{+}$relative to the disulfide were also observed.

${ }^{b}$ : Traces of a non-acetylated truncated peptide containing a $\mathrm{N}$-terminal Cys residue were observed in the LC-MS analysis of the mixture. This co-product was attributed to in situ $N \rightarrow S$ shift at Xaa-Cys sites followed by trans-thioesterification, as reported by MacMillan. ${ }^{8}$ Note that the ion chromatogram signal is not representative of the actual proportion of this peptide, as compared with the HPCL-UV analysis. Smaller peptides very probably lead to a higher BPC signal due to greater ionization.

': [1-50] AhPDF1.5 corresponds to a co-product arising from hydrolysis of peptide crypto-thioester 6'. [1-50] AhPDF1.5 proportion was evaluated to $2 \%$ relative to 7 by integration of the corresponding extracted ion chromatograms, neglecting the eventual differences in terms of ionization of the two compounds.

d: The calculated $\mathrm{m} / \mathrm{z}$ value corresponds to a $\left[\mathrm{M}+\mathrm{NH}_{4}\right]^{+}$form $\left(\mathrm{C}_{16} \mathrm{H}_{18} \mathrm{NO}_{4} \mathrm{~S}_{2}\right)$, a $[\mathrm{M}+\mathrm{Na}]^{+}$species being also observed but not $[\mathrm{M}+\mathrm{H}]^{+}$. A minor peak consistent with decarboxylation to yield a benzyl cation (see note a) is also observed. 


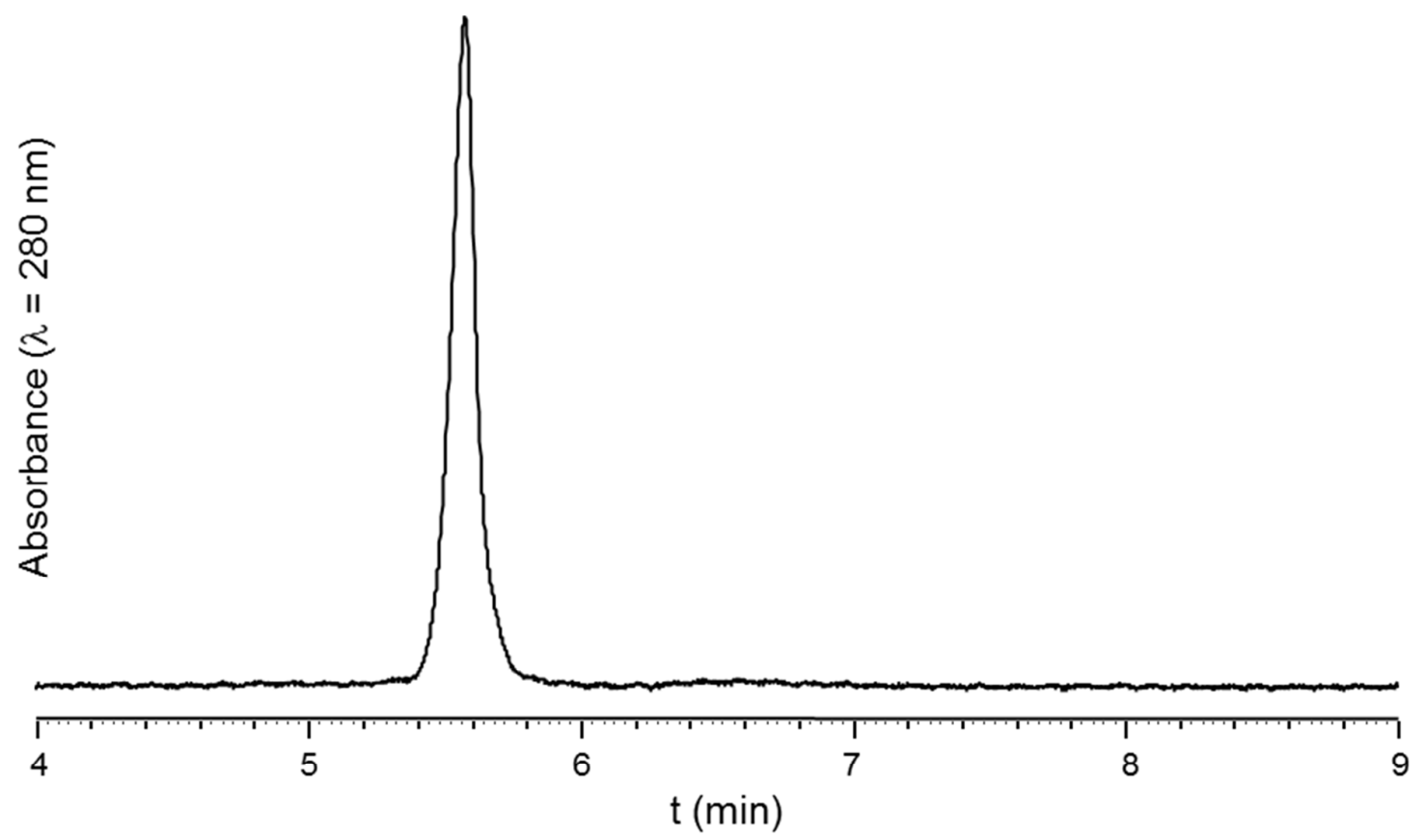

Supplementary figure S25: HPLC trace of purified 7. 